\title{
New Horizons in C-F Activation by Main Group Electrophiles
}

Grant number for the previous grant period (at Brandeis University): DE-FG02-06ER15815

Project title for the previous grant period: Catalysis of C-F activation by highly electrophilic Si compounds

PI Information:

Oleg V. Ozerov, Professor of Chemistry

Department of Chemistry, TAMU - 3255

Texas A\&M University, College Station, TX 77842

Phone: 979-845-5870; email: ozerov@chem.tamu.edu ;

URL: http://www.chem.tamu.edu/rgroup/ozerov/

DOE Office of Science Program Office: Basic Energy Sciences

DOE/Office of Science Technical Contact: Raul Miranda, Raul.Miranda@science.doe.gov (Division of Chemical Sciences, Geosciences, and Biosciences; Catalysis and Chemical Transformations program)

\section{Introduction.}

\section{I-A. Overview and significance.}

Fluoroorganic materials benefit our society through a number of dedicated uses. ${ }^{1}$ Fluoropolymers possess many unique and useful properties owing to their inertness, strength and "non-stick" properties. ${ }^{2}$ About $30 \%$ of agrochemicals and $10 \%$ of pharmaceuticals contain carbon-fluorine bonds. ${ }^{3}$ Perfluoroalkane liquids have been explored as artificial blood substitutes because of their inertness and high $\mathrm{O}_{2}$ solubility. They have also attracted interest as an alternative, "fluorous" medium for catalytic processes owing to their coincident hydrophobicity and oleophobicity. ${ }^{4}$ The main "green" chemistry ${ }^{5}$ benefit of a reaction medium that is easily separable from the products is the reduction of solvent waste.

On the other hand, some of the fluoroorganics that brought technological advances into our daily lives were later understood to have deleterious effects on the environment. Perfluoroctanesulfonic and perfluorooctanoic acids and their derivatives, valuable surfactants and additives in fluoropolymer processing, have been recently shown to be toxic, widely spread in the biota, and highly persistent. ${ }^{6}$ The most publicly known example of fluoroorganics' effect on the environment is undoubtedly the story of chlorofluorocarbons (CFCs or chlorofluoroalkanes). They revolutionized refrigeration and cooling, but were eventually found to be destructive towards the ozone layer. ${ }^{7}$ The 1987 Montreal Protocol on Substances that Deplete the Ozone Layer ${ }^{8}$ that plotted the course for the phase-out of CFCs stands out as one successful example of international environmental legislation. The use of CFCs has been substantially reduced and the ozone hole expansion curtailed. ${ }^{9}$ Under the Montreal protocol, the chief replacements for CFCs have been hydrofluorocarbons (HFCs or partially fluorinated alkanes) that are ozone-safe. Hydrochlorofluorocarbons (HCFCs or partially chlorinated/fluorinated alkanes) served a transitional role and possess diminished ozone-destroying potential.

What is less well-known is that CFCs are very potent greenhouse gases. ${ }^{10}$ In a rare example of a positive unintended consequence, the reduction of CFC emissions under the Montreal protocol not only protected the ozone layer, but also mitigated the contribution to global warming. ${ }^{10}$ However, this mitigation is diminished by that the replacements for CFCs (HFCs and HCFCs) are themselves only 
somewhat less potent greenhouse gases. ${ }^{10,11}$ Other polyfluoroalkanes besides those used in refrigeration are also on the greenhouse effect "radar". The bromine-containing relatives of CFCs (halons) that find uses in fire extinguishing and other areas possess very high GWPs. ${ }^{12}$ Perfluorocarbons (perfluoroalkanes, or PFCs) are an unwanted by-product in aluminum manufacture ${ }^{13}$ where electrolysis cells with carbon anodes and fluoride-containing melts generate $\mathrm{CF}_{4}$ and larger PFCs. PFCs are also broadly used in semiconductor industry for etching silicon wafers. ${ }^{14}$ The GWP values for PFCs are also very high and they possess atmospheric lifetimes so high (up to 50,000 yrs) as to be considered eternal on the timescale of human civilization. ${ }^{15}$ The atmospheric lifetimes of HFCs, CFCs, and HCFCs are not as high, but still count in tens and hundreds of years. Together these fluorinated pollutants have been referred to as "super-greenhouse gases"16 (we will refer to them as collectively as SGHGs in this proposal). Because of the long lifetimes and of the very high GWPs (thousands of times that of $\mathrm{CO}_{2}$ ) the emissions of SGHGs contribute very significantly to radiative forcing. By various estimates, ${ }^{17}$ SGHG emissions account for $10-20 \%$ of the net human activity effects and these numbers grow in models for the future. ${ }^{10,11}$ There are virtually no natural sources of SGHGs and long lifetimes mean very slow removal from the atmosphere. The importance of SGHGs in effects on climate is recognized by both international organizations and the US government. SGHGs feature prominently in IPCC reports ${ }^{18}$ and in the Kyoto Protocol documentation, ${ }^{19}$ while the Environmental Protection Agency's website features a dedicated section on high GWP gases (=SGHGs). ${ }^{20}$

Reductions in the use of SGHGs and supplanting the need for them with new technologies are ultimately the way to curtail their release into the environment. However, this requires innovation and time for implementation. Thus, destruction of the stockpiles and of the generated waste streams is necessary to alleviate the effect. ${ }^{21}$ For example, leakage of CFCs into the atmosphere from existing stockpiles alone is expected to contribute 6 billion ton $\mathrm{CO}_{2}$-equiv before $2015 .{ }^{21}$ Interestingly, nuclear energy production accounts for a notable fraction of CFC emissions arising from heat exchange equipment in enrichment schemes. ${ }^{22}$ One way to think of the benefit of minimizing SGHG emissions is that removing their contribution buys extra years (in terms of the overall global warming results) for solving the ultimately more demanding $\mathrm{CO}_{2}$ problem. ${ }^{10,11}$

Different methods for the destruction of various SGHGs do exist, however, the high stability especially of PFCs exacts high demands on such processes, leading to consideration of such exotic options as treatment with sodium vapor at $830{ }^{\circ} \mathrm{C} .{ }^{23}$ Plasma methods have been used, ${ }^{24}$ as well as decomposition with various element oxides. ${ }^{25}$ Temperatures of $400-600{ }^{\circ} \mathrm{C}$ are referred to as relatively low in PFC abatement. ${ }^{26}$ Burdeniuc and Crabtree described a ca. $250{ }^{\circ} \mathrm{C}$ process for decomposition of CFCs with alkali metal oxalates, but of PFCs, only those that can aromatize ${ }^{27}$ (6-membered rings) reacted. ${ }^{28}$ Aromatization of cyclic perfluoroalkanes has also been reported with thiolates. ${ }^{29}$

All in all, there is room for improvement in processes for conversion of SGHGs to environmentally benign compounds and this provides one motivation for the study of C-F bond activation. On a more fundamental level, activation of C-F bonds is a noteworthy challenge because C-F is arguably the most inert, unreactive functionality in organic chemistry. ${ }^{1}$ The problem of C-F bond activation has historically drawn practitioners of transition metal-based catalysis, in which the cleavage of the C-F bond is typically conceived to proceed reductively, through either oxidative addition of C-F to a metal center or via oneelectron reduction. ${ }^{30}$ The subject of carbon-fluorine bond activation was recently thoroughly reviewed from an organic vantage point by Amii and Uneyama. ${ }^{3}$ The transition metal catalysis has worked better for polyfluoroarenes and fluoroalkenes, which possess $\pi$-systems that provide a relatively low energy avenue for attack on the molecule. ${ }^{31,32}$ Aliphatic compounds with only $\mathrm{C}\left(\mathrm{sp}^{3}\right)$-F bonds present a greater fundamental challenge, generally lacking either Lewis basicity or acidity (or electrophilicity or 
nucleophilicity, respectively, in kinetic terms), with correspondingly less success in evidence. . $3,34^{3}$ Increased fluorination of alkyl chains ostensibly exacerbates the problem. The C-F bonds are stronger in perfluoroalkyl chains and the carbon chain is also more sterically and electronically shielded by the fluorine atoms. ${ }^{30}$ As with any strong bond "activation and functionalization", part of the challenge is how to integrate the event of breaking the reticent bond into a catalytic cycle, especially in a process that converts $\mathrm{C}-\mathrm{F}$ bonds to other $\mathrm{C}$-element bonds. Conceptually, the simplest transformation of a $\mathrm{C}-\mathrm{F}$ bond is to a $\mathrm{C}-\mathrm{H}$ bond, which can be termed hydrodefluorination (HDF).

\section{I-B. Our approach.}

We became interested in developing new methods for HDF and other types of C-F bond conversion in polyfluoroalkanes under mild conditions. Much of the previous effort in C-F activation concentrated on reductive cleavage of the C-F bond (Figure 1), either by strong reducing agents (e.g., reactive metals) or by electron-rich transition metal centers. $^{30}$ In the transition metal community the mechanistic allure

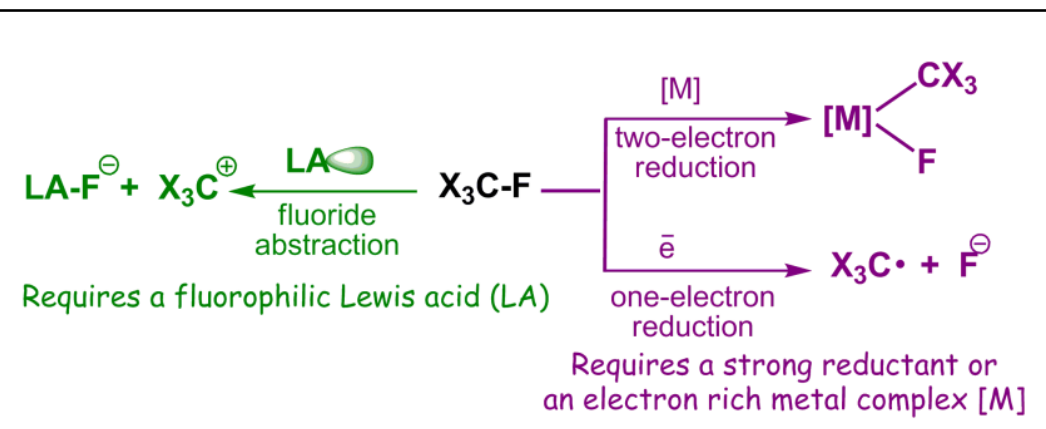

Figure 1. Reductive and heterolytic C-F cleavage strategies of C-F oxidative addition (not always concerted oxidative addition) has been particularly strong. We were attracted to a conceptually different approach to C-F activation, where the key C-F cleavage proceeds by a Lewis acid abstraction of fluoride rather than a redox event. Conventional acids, such as $\mathrm{SiO}_{2}, \mathrm{TiO}_{2}$ or concentrated $\mathrm{H}_{2} \mathrm{SO}_{4},{ }^{35}$ require high temperatures for cleavage of $\mathrm{C}-\mathrm{F}$ bonds in perfluoroalkyl groups. Inorganic Lewis acids (e.g., $\mathrm{SbF}_{5}$, ACF or $\mathrm{AlCl}_{\mathrm{x}} \mathrm{F}_{3-\mathrm{x}}$ ) have substantial history in industrial processes involving polyfluoroorganics and activation of $\mathrm{C}-\mathrm{Cl}$ and $\mathrm{C}-\mathrm{F}$ bonds, ${ }^{36}$ but they appear incompatible with the concept of hydrodefluorination and often operate only at high temperature, as well.

In 2005, we reported an execution of the non-redox approach under ambient conditions by using a silylium $\left(\mathrm{R}_{3} \mathrm{Si}^{+}\right)$Lewis acid. $^{37}$ Our silylium-catalyzed process was conceived as an implementation of the two half-reactions shown in Scheme 1-A. These half-reactions can be described in Lewis acid-base terms as transfer of fluoride from a carbenium ion (carbocation) $\mathrm{R}_{3} \mathrm{C}^{+}$to a silylium cation $\mathrm{X}_{3} \mathrm{Si}^{+}$complemented by hydride transfer from $\mathrm{X}_{3} \mathrm{Si}^{+}$to $\mathrm{R}_{3} \mathrm{C}^{+}$. The

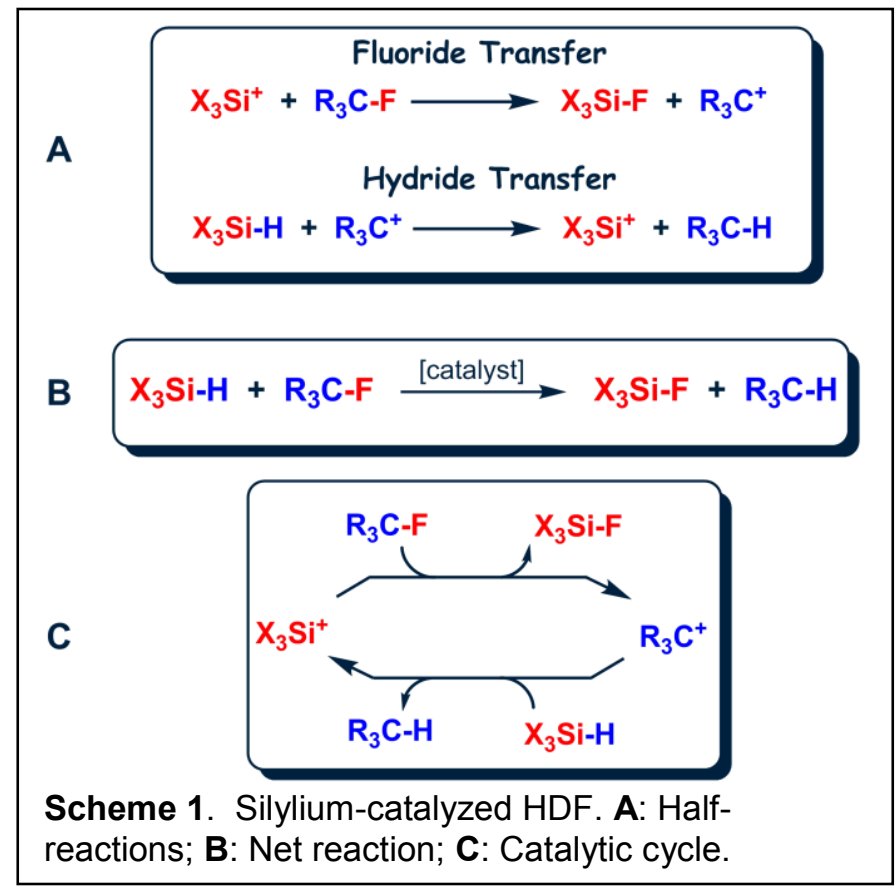
sum of the two half reactions is the net reaction (Scheme 1-B), a C-F/Si-H metathesis. The proposed 
catalytic cycle (Scheme 1-C) is a sequence of the two half-reactions in Scheme 1-A. The guiding precedent for our silylium work is the gas-phase studies of Krause and Lampe who studied collisions of $\mathrm{H}_{3} \mathrm{Si}^{+}$with $\mathrm{CF}_{4}$ and of $\mathrm{CF}_{3}{ }^{+}$with $\mathrm{SiH}_{4}$. Their findings indicated that "the major reaction of positive ions containing fluorine is $\mathrm{H}^{-}$abstraction and the major reaction of positive silicon ions with $\mathrm{CF}_{4}$ is $\mathrm{F}^{-}$ abstraction". ${ }^{38}$ In the condensed phases, silylium cations and silylium cation-like behavior have proven to be a substantial synthetic challenge, in some ways more so than carbocations. ${ }^{39}$ Largely through the efforts of Reed and Lambert, utilization of weakly coordinating anions such as $\left[\mathrm{B}\left(\mathrm{C}_{6} \mathrm{~F}_{5}\right)_{4}\right]^{-}$and halogenated carboranes led to the isolation of trialkylsilylium derivatives that approach the free silylium ion character ${ }^{40,41}$ as well as a true silylium cation with bulky aryl substituents. ${ }^{42}$ Even with the state-ofthe-art weakly coordinating anions, silylium cations and many carbocations are likely to form adducts with the anion, the solvent or the reagents/products of our catalytic reactions. We will discuss "cations" with this understanding in mind.

Utilizing $\mathrm{Et}_{3} \mathrm{SiH}$, successful HDF was recorded for a series of benzotrifluorides and alkyl fluorides. ${ }^{37}$ In general, increased fluorination in the substrate led to slower reactivity, and appeared consistent with the fluoride transfer reaction in Scheme 1-A being rate-limiting. Only $\mathrm{C}\left(\mathrm{sp}^{3}\right)$-F bonds were attacked. Isolation of $\mathrm{Et} 3 \mathrm{Si}\left[\mathrm{B}\left(\mathrm{C}_{6} \mathrm{~F}_{5}\right)_{4}\right]$ proved unnecessary and the more robust $\mathrm{Ph}_{3} \mathrm{C}\left[\mathrm{B}\left(\mathrm{C}_{6} \mathrm{~F}_{5}\right)_{4}\right]$ could be conveniently used as a pre-catalyst. In the presence of excess $\mathrm{Et}_{3} \mathrm{SiH}$ in the reaction mixture, it was rapidly converted into $\left.\mathrm{Et} \mathrm{Si}_{3} \mathrm{Si}\left(\mathrm{C}_{6} \mathrm{~F}_{5}\right)_{4}\right]$ in situ. Related work on conversion of $\mathrm{C}-\mathrm{O}$ bonds to $\mathrm{C}-\mathrm{H}$ bonds was reported by Gevorgyan and Yamamoto, who used $\mathrm{B}\left(\mathrm{C}_{6} \mathrm{~F}_{5}\right)_{3}$ to generate small concentrations of $\mathrm{Et}_{3} \mathrm{Si}\left[\mathrm{HB}\left(\mathrm{C}_{6} \mathrm{~F}_{5}\right)_{3}\right]$ in situ. ${ }^{43}$

Note on terminology: It is possible to describe the reactivity in Scheme 1 as chain reactions and not catalysis. This is a semantic point that does not bear on the results (consider also "general acid catalysis ${ }^{, 44}$ ) and we will discuss the chemistry in terms of catalysis and catalysts, also omitting for brevity the distinction between a catalyst and a pre-catalyst (e.g., $P h_{3} C\left[B\left(C_{6} F_{5}\right)_{4}\right]$ for Scheme 1).

\section{Progress report.}

General information. During the previous grant period (08/15/2006 - 12/31/2009), the PI was based at Brandeis University (415 South Street, Waltham, MA 02454). The PI (and most of the PI's research group) relocated to Texas A\&M University in January 2009 while retaining an Adjunct Professor appointment at Brandeis for 2009. Because of the move, the research activities in the $2^{\text {nd }}$ half of 2008 and the $1^{\text {st }}$ half of 2009 were diminished. On the one hand, it was not wise or even possible to hire new postdoctoral personnel in late 2008 or very early 2009 to replace the departures of 2008 . On the other hand, the time elapsed for the setup of new laboratories at TAMU in 2009 limited research options for students moving from Brandeis and for newly recruited TAMU students. No-cost extension for an additional 4.5 months beyond the original period was requested and approved.

Focus during the previous period. Our preliminary study in 2005 demonstrated the feasibility of silylium catalysis using $\left[\mathrm{B}\left(\mathrm{C}_{6} \mathrm{~F}_{5}\right)_{4}\right]^{-}$as the supporting anion. However, this anion, although resistant to $\mathrm{Et}_{3} \mathrm{Si}^{+}$, displayed very limited stability in HDF reactions and was quickly identified as the "weak link". Two other groups subsequently used this anion in similar HDF chemistry and reported similarly limited reactivity. ${ }^{45}$ The efforts during the previous period were aimed at a) advancing the HDF reactivity with improvement in scope and catalyst longevity; b) extending C-F activation beyond HDF; c) generating insight about the elementary steps of the reaction and potential intermediates.

Douvris, C.; Ozerov, O. V. "Hydrodefluorination Of Perfluoroalkyl Groups Using Silylium-Carborane Catalysts", Science 2008, 321, 1188 and Douvris, C.; Nagaraja, C. M.; Chen, C.-H.; Foxman, B. M.; Ozerov, O. V. "Hydrodefluorination and Other 


\section{Hydrodehalogenation of Aliphatic Carbon-Halogen Bonds Using Silylium Catalysis",}

submitted.

Our pivotal task was the identification of weakly coordinating anions ${ }^{46}$ that are similar to $\left[\mathrm{B}\left(\mathrm{C}_{6} \mathrm{~F}_{5}\right)_{4}\right]^{-}$ in terms of weak basicity but are superior in terms of stability. As we had proposed, halogenated derivatives of the $\left[\mathrm{HCB}_{11} \mathrm{H}_{11}\right]^{-}$carborane anion (Figure 2) proved equal to the task (Scheme 2). Our study benefited from the sophistication in the chemistry of carboranes brought to the fore by groups of Michl, Strauss, Reed, Xie and others (recently reviewed by Korbe et al. ${ }^{47}$; studies by the Reed group are particularly relevant. ${ }^{48,49}$ Carborane anions have been shown to be compatible with the highest levels of Brønsted and Lewis (e.g., silylium and carbocations) acidity in the condensed phase even under harsh conditions. For instance, $\mathrm{H}\left[\mathrm{HCB}_{11} \mathrm{Cl}_{11}\right]$, the strongest known Brønsted acid, can be sublimed at $200^{\circ} \mathrm{C}$ without decomposition. ${ }^{50} \mathrm{In}$ contrast, $\left[\mathrm{B}\left(\mathrm{C}_{6} \mathrm{~F}_{5}\right)_{4}\right]^{-}$is not

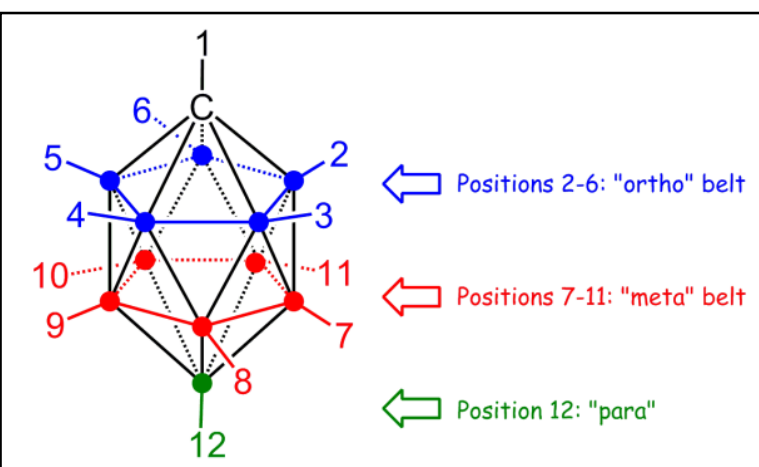

Figure 2. Representation of the monocarbacloso-dodecaborate(-) $\left[\mathrm{HCB}_{11} \mathrm{H}_{11}\right]^{-}$anion, or carborane (dots at vertices 2-12 represent boron atoms; each vertex is capped with an $\mathrm{H}$ atom). $\quad\left[\mathrm{HCB}_{11} \mathrm{H}_{5} \mathrm{X}_{6}\right]^{-}$anions bear $X$ on para and meta vertices; $\left[\mathrm{HCB}_{11} \mathrm{X}_{11}\right]^{-}$bear $\mathrm{X}$ on all $\mathrm{B}$ vertices. compatible with very high levels of Brønsted acidity. It is probably also incompatible with reactive carbocations. Notably, the other common fluorinated tetraarylborate, $\left[\mathrm{B}\left(\mathrm{C}_{6} \mathrm{H}_{3}\left(\mathrm{CF}_{3}\right)_{2}\right)_{4}\right]^{-}$, possesses benzylic $\mathrm{CF}_{3}$ groups and is not tolerant of even silylium cations. ${ }^{52}$

We used $\mathrm{C}_{6} \mathrm{~F}_{5} \mathrm{CF}_{3}$ as a test substrate to compare the reactivities of catalysts with different anions. Our tests showed that even in the reactions where $\left[\mathrm{B}\left(\mathrm{C}_{6} \mathrm{~F}_{5}\right)_{4}\right]^{-}$ rapidly decomposed, the carboranes were completely unscathed. Whereas with $\left[\mathrm{B}\left(\mathrm{C}_{6} \mathrm{~F}_{5}\right)_{4}\right]^{\text {, }}$, the turnover numbers (TON) even with the easiest substrates were limited to $<100$, carborane anions supported HDF of even perfluoroalkyl-containing substrates with TON's in the thousands, with no evidence of anion decomposition by ${ }^{11} \mathrm{~B}$ NMR. The activity of carborane-supported catalysts was in order of $\left[\mathrm{HCB}_{11} \mathrm{H}_{5} \mathrm{Br}_{6}\right]^{-}<\left[\mathrm{HCB}_{11} \mathrm{Cl}_{11}\right]^{-}<$ $\left[\mathrm{HCB}_{11} \mathrm{H}_{5} \mathrm{Cl}_{6}\right]^{-}$. Reed previously determined that the basicity decreases in the series $\left[\mathrm{HCB}_{11} \mathrm{H}_{5} \mathrm{Br}_{6}\right]^{-}>$ $\left[\mathrm{HCB}_{11} \mathrm{H}_{5} \mathrm{Cl}_{6}\right]^{-}>\left[\mathrm{HCB}_{11} \mathrm{Cl}_{11}\right]^{-}$, albeit the differences are small. $^{50}$ In that context, the lower activity of $\left[\mathrm{HCB}_{11} \mathrm{H}_{5} \mathrm{Br}_{6}\right]^{-}$is logical, but the higher activity of $\left[\mathrm{HCB}_{11} \mathrm{H}_{5} \mathrm{Cl}_{6}\right]^{-}$vs. $\left[\mathrm{HCB}_{11} \mathrm{Cl}_{11}\right]^{-}$is surprising. The reasons behind this apparent anomaly remain unclear. Curiously, in the polymerization of cyclo- $\left[\mathrm{NPCl}_{2}\right]_{3}$ by $\mathrm{R}_{3} \mathrm{Si}$ [carborane], a similar discrepancy between lower
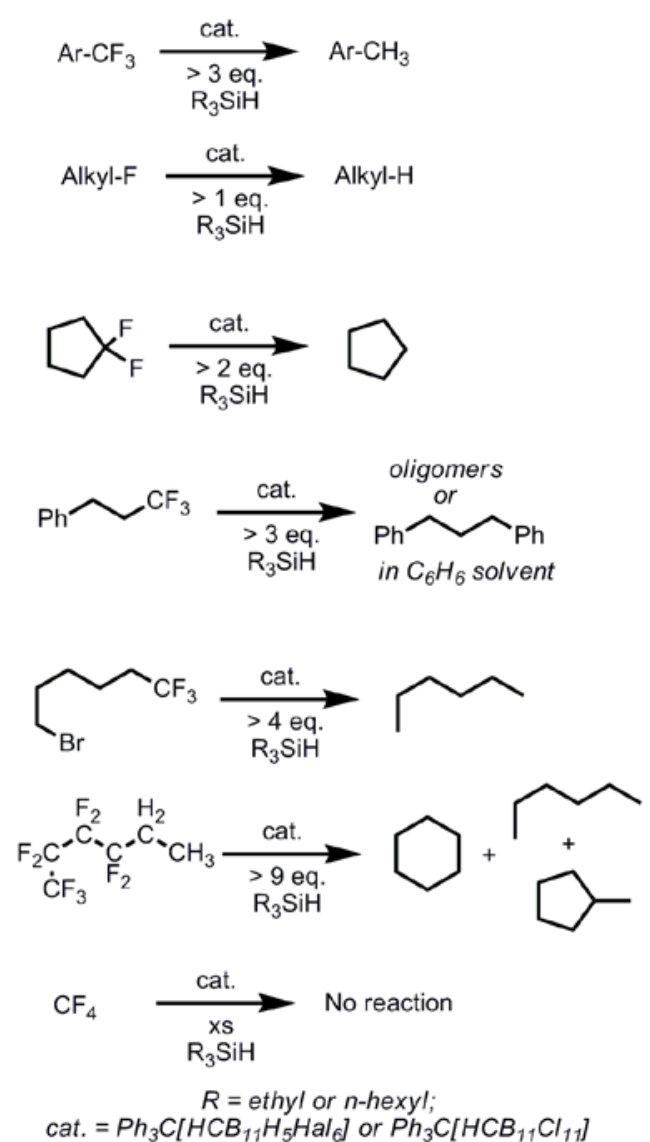

Scheme 2. HDF reactions basicity and higher activity was reported. ${ }^{33}$ It is important to emphasize, however, that all three 
carboranes were able to carry HDF reactions to completion. We obtained an X-ray structure of $\mathrm{Et}_{3} \mathrm{Si}\left[\mathrm{HCB}_{11} \mathrm{H}_{5} \mathrm{Cl}_{6}\right]$ (Figure 3) whose structural features are consistent with the previously published trialkylsilylium-carborane structures. ${ }^{39,41}$

The HDF reactions of $\mathrm{C}_{6} \mathrm{~F}_{5} \mathrm{CF}_{3}$ in $\mathrm{C}_{6} \mathrm{H}_{4} \mathrm{Cl}_{2}$ as solvent resulted in large amounts of by-products of the formula $\mathrm{C}_{6} \mathrm{~F}_{5} \mathrm{CH}_{2} \mathrm{C}_{6} \mathrm{H}_{3} \mathrm{Cl}_{2}$. These are ultimate products of the Friedel-Crafts attack of the incipient carbocations on dichlorobenzene. The Friedel-Crafts reactivity did not halt the catalysis and itself proceeded catalytically. We proposed a tentative mechanism (Scheme 4). The key step is the protonation of $\mathrm{Et}_{3} \mathrm{SiH}$ by the Wheland intermediate

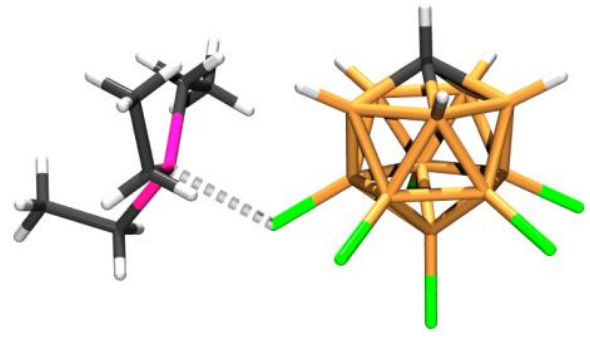

Figure 3. Representation of the X-ray structure of $\mathrm{Et}_{3} \mathrm{Si}\left[\mathrm{HCB}_{11} \mathrm{H}_{5} \mathrm{Cl}_{6}\right]$ (= protonated arene) that regenerates $\mathrm{Et}_{3} \mathrm{Si}^{+}$. We detected the expected $\mathrm{H}_{2}$ by-product. Reed isolated fluorinated carbocations with $\left[\mathrm{HCB}_{11} \mathrm{I}_{11}\right]^{-}$as the counterion through similar stoichiometric Friedel-Crafts reactions. ${ }^{54}$

We have also investigated $\mathrm{HDF}$ of $\mathrm{PhCH}_{2} \mathrm{CH}_{2} \mathrm{CF}_{3}$, and $n-\mathrm{C}_{4} \mathrm{~F}_{9} \mathrm{C}_{2} \mathrm{H}_{5}$ as examples of substrates with perfluoroalkyl groups that are not benzylic. With $\mathrm{PhCH}_{2} \mathrm{CH}_{2} \mathrm{CF}_{3}$, extensive Friedel-Crafts chemistry took place: either

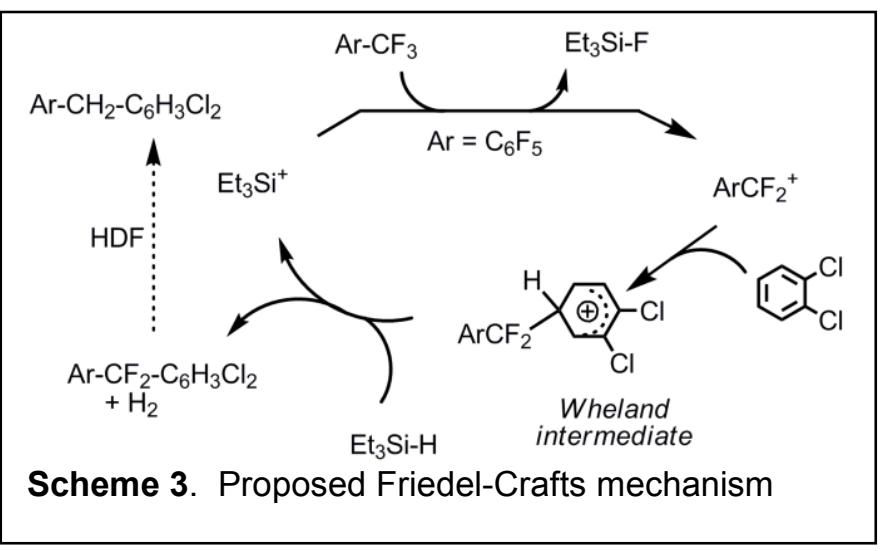
intramolecularly, when reaction was done neat, or intermolecularly with benzene solvent. The latter allowed for high yield formation of 1,3-diphenylpropane as the chief product. This purposeful utilization of the Friedel-Crafts chemistry thus led to the conversion of a $\mathrm{CF}_{3}$ group into a $\mathrm{CH}_{2} \mathrm{Ph}$ group. Although the utility of Friedel-Crafts chemistry is limited, it does afford a path for $\mathrm{C}-\mathrm{C}$ coupling of $\mathrm{C}-\mathrm{F}$ bonds. $n$ $\mathrm{C}_{4} \mathrm{~F}_{9} \mathrm{C}_{2} \mathrm{H}_{5}$ was the most difficult substrate, reacting but sluggishly, but nonetheless complete consumption was achieved. We were able to identify several (presumably, as a result of carbocation isomerization) $\mathrm{C}_{6}$ hydrocarbons as the organic products of the reaction. This constitutes the first example of a room temperature HDF of a perfluoroalkyl group.

In the second publication, we reported the extended scope of HDF with silylium carborane catalysts including different benzotrifluorides, primary and secondary alkyl fluorides, gem-difluoroalkanes, as well as a substrate like $\mathrm{Br}\left(\mathrm{CH}_{2}\right)_{5} \mathrm{CF}_{3}$. For all of these, we have achieved high-TON HDF. In the presence of aromatic rings, extensive Friedel-Crafts chemistry was observed; otherwise the expected HDF products were formed. The conversion of $\mathrm{Br}\left(\mathrm{CH}_{2}\right)_{5} \mathrm{CF}_{3}$ to $\mathrm{n}$-hexane indicated that hydrodebromination $(\mathrm{HDBr})$ is viable for the silylium catalysis. However, we observed no reaction with $\mathrm{CF}_{4}$ or perfluoromethylcyclohexane even under forcing $\left(90{ }^{\circ} \mathrm{C}\right)$ conditions. This outlines the limit of the scope of HDF with trialkylsilanes - perfluoroalkyl chains with alkyl substituents are consumed, but fully fluorinated alkanes are not.

We undertook an investigation of hydrodechlorination $(\mathrm{HDCl})$ in greater detail. The same catalytic system was able to readily consumer benzotrichlorides and simple alkyl chlorides, performing similarly to HDF (Scheme 4). In order to establish the preference of the catalytic system for different halides, we 
performed a series of competition reactions. We discovered that in the same-vessel competition HDF of $\mathrm{C}_{6} \mathrm{~F}_{5} \mathrm{CF}_{3}$ proceeded much more slowly than $\mathrm{HDCl}$ of $\mathrm{C}_{6} \mathrm{~F}_{5} \mathrm{CCl}_{3}$ (Figure 4). In contrast, for primary alkyl halides, HDF was much faster than $\mathrm{HDCl}$, which in turn was faster than $\mathrm{HDBr}$ and hydrodeiodination (HDI) (Figure 5). These results are contradictory only at a cursory glance. If the first halide abstraction from $\mathrm{Ar}_{-} \mathrm{CHal}_{3}$ is rate-limiting (consistent with lack of observable $\mathrm{ArCHHal}_{2}$ or $\mathrm{ArCH}_{2} \mathrm{Hal}$ intermediates), then the abstraction of chloride from $\mathrm{C}_{6} \mathrm{~F}_{5} \mathrm{CCl}_{3}$ generates a different carbocation than the abstraction of fluoride from $\mathrm{C}_{6} \mathrm{~F}_{5} \mathrm{CF}_{3}$, whereas abstraction of halide from monohaloalkanes generates the same (or nearly the same) carbocation. In short, the preference for $\mathrm{F}$ vs $\mathrm{Cl}$ or even $\mathrm{Br}$ is complex and depends on the overall structure of the substrate. Nonetheless, all mixtures of CHal could react to completion with total hydrodehalogenation.

$\mathrm{HDCl}$ (but not HDF) with silanes with weak $\mathrm{Si}-\mathrm{H}$ bonds (e.g., $\left.\left(\mathrm{Me}_{3} \mathrm{Si}\right)_{3} \mathrm{SiH}\right)$ functioning as hydrogen atom donors has been reviewed. ${ }^{55}$ Our chemistry with $\mathrm{Et}_{3} \mathrm{SiH}$ did not proceed with standard radical initiators.

The catalytic system here and in all other C-Hal activation chemistry in our work displayed constant preference for the activation of $\mathrm{C}\left(\mathrm{sp}^{3}\right)$-Hal bonds and no evidence for attack of $\mathrm{C}\left(\mathrm{sp}^{2}\right)$-Hal bonds. This is

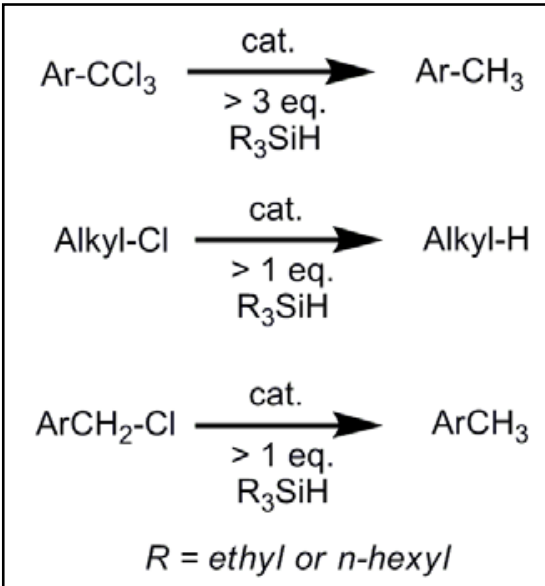

Scheme 4. Silylium-catalyzed $\mathrm{HDCl}$ completely orthogonal to the transition metal chemistry, where polyfluoroarenes are the most reactive substrates. $^{30}$ Hexafluorobenzene is the most common substrate in transition metal catalysis; we used it as a convenient unreactive internal ${ }^{19} \mathrm{~F}$ NMR standard!

In the $\mathrm{HDF}$ and $\mathrm{HDCl}$ reactions that went to completion, we routinely observed TON in the 1,000-5,000 range. We have not been able to push HDF past 40,000 TON and that with only incomplete conversion. Such low catalyst loadings may be sensitive to ppm levels of basic impurities,

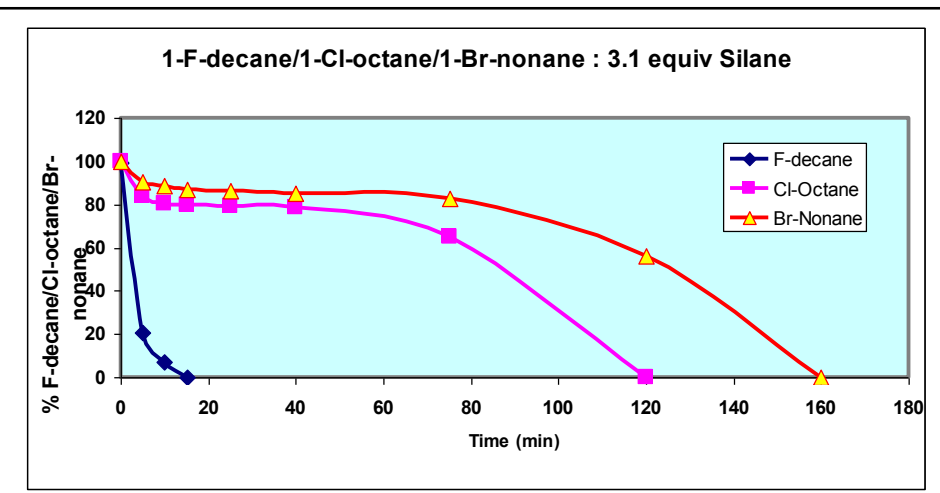

Figure 5. Preferential HDF over $\mathrm{HDCl}$ over $\mathrm{HDBr}$ among alkyl halides however, this does not appear to be the limiting factor. Reactions reached 40,000 TON in an asymptotic fashion, with slowly decreasing rate over several days. We contend that this is more consistent with self-

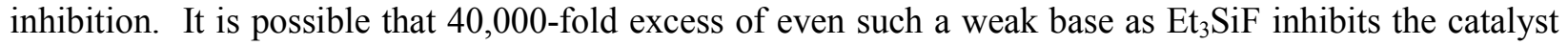
(for example if pre-equilibrium dissociation of $\left[\mathrm{Et}_{3} \mathrm{Si}-\mathrm{F}-\mathrm{SiEt}_{3}\right]^{+}$was necessary. We observed exactly the same high-TON effects in Al chemistry (vide infra). 
Gu, W.; Haneline, M. R.; Douvris, C., "Carbon-Carbon Coupling of C(sp $\left.\mathbf{s}^{3}\right)-\mathrm{F}$ Bonds Using Alumenium Catalysis", J. Am. Chem. Soc., 2009, 131, 11203.

We surmised that a catalytic cycle similar the Si one (Scheme 1) can be based on Al, another fluorophile. We further hypothesized that the more polar Al-C bonds might allow for transfer of alkyl groups from Al to carbocations. The proposed cycle and the overall ideal "alkylative defluorination" (AlkDF) reaction is depicted in Scheme 5. This scheme relies on the fluorophilicity of the $\mathrm{X}_{2} \mathrm{Al}^{+}$(alumenium cation). ${ }^{56}$ We utilized $\mathrm{Et}_{2} \mathrm{Al}\left[\mathrm{HCB}_{11} \mathrm{H}_{5} \mathrm{Br}_{6}\right]$, first reported by Sen and Reed, ${ }^{57}$ as our catalyst. A summary of our findings follows in the text and in Scheme 6.

- AlkDF proceeded with C-F substrates similar to the Si-based $\mathrm{HDF}$, up to $\mathrm{Ph}\left(\mathrm{CH}_{2}\right)_{2} \mathrm{CF}_{3}$, but not with $n-\mathrm{C}_{4} \mathrm{~F}_{9} \mathrm{C}_{2} \mathrm{H}_{5}$.

- Friedel-Crafts side reactions (catalytic) were also observed, but were less competitive than in HDF with Si.

- $\mathrm{Me}_{3} \mathrm{Al}$ gave clean conversion of $\mathrm{C}-\mathrm{F}$ bonds to C-Me bonds. Triethyl- and triisobutylaluminum produced a mixture of products corresponding to competitive transfer of either alkyl or a $\beta$-hydride from Al.

- Approximately 1.1-1.4 alkyl (= X) groups in $\mathrm{X}_{3} \mathrm{Al}$ or $0.15{ }^{\mathrm{i}} \mathrm{Bu}$ groups from ${ }^{i} \mathrm{Bu}_{2} \mathrm{AlF}$ could be used to replace $\mathrm{C}-\mathrm{F}$ bonds.

- Trialkylaluminum without an alumenium catalyst did effect AlkDF, but much more slowly, hardly at all in non-polar solvents. In addition, in non-catalyzed reactions,

Alkylative defluorination (AlkDF)

$\mathrm{X}_{3} \mathrm{C}-\mathrm{F}+\mathrm{R}_{2} \mathrm{Al}-\mathrm{R} \longrightarrow \mathrm{X}_{3} \mathrm{C}-\mathrm{R}+\mathrm{R}_{2} \mathrm{Al}-\mathrm{F}$

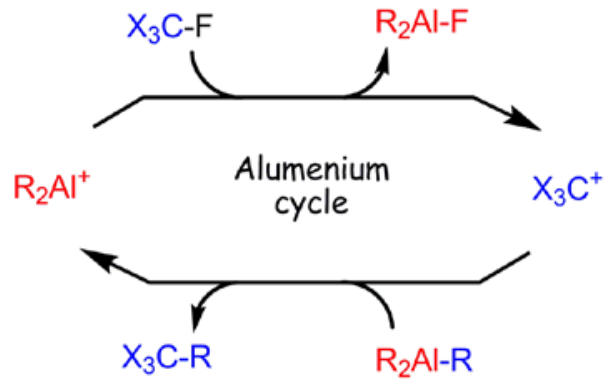

Scheme 5. Proposed AlkDF mechanism dehydrofluorination to alkenes was observed as a significantly competitive process. Noncatalyzed AlkDF reactions of trialkylaluminums have been more deeply studied by Terao et al., with similar outcomes. ${ }^{58}$

- The reaction tolerated the presence of supracatalytic amounts of water, presumably because of the "self-scrubbing" properties of trialkylaluminums. Methylaluminoxane (MAO) was not only tolerated, but appeared to effect AlkDF more efficiently without a catalyst than trialkyluminums without a catalyst. The high Lewis acidity of MAO and the scrubbing effect of organoaluminums mimic their benefits as co-catalysts in olefin polymerization. ${ }^{59}$ 
- Utilization of a mixture of $\mathrm{Me}_{3} \mathrm{Al}$ and $\mathrm{Et}_{3} \mathrm{SiH}$ resulted in both $\mathrm{AlkDF}$ and $\mathrm{HDF}$ of a benzotrifluoride, indicating compatibility of the two processes, albeit without selectivity.

\section{Gusev, D. G.; Ozerov, O. V. "Hydride and Fluoride Affinities of a Series of Carbenium and Silylium Cations in the Gas Phase and $\mathrm{C}_{6} \mathrm{H}_{5} \mathrm{Cl}$ Solution", submitted.}

As the first step towards understanding of the underlying basics of the catalytic process, we undertook a computational study of hydride and fluoride affinities (HA and FA) of various $\mathrm{X}_{3} \mathrm{Si}^{+}$and $\mathrm{R}_{3} \mathrm{C}^{+}$cations. This work was carried out in collaboration with Prof. Dmitri Gusev of Wilfrid Laurier University (Waterloo, Canada). We particularly sought insight into the lack of reactivity with perfluoroalkanes and into whether it is possible to modulate the reactivity by the choice of silane. The calculated values of $\mathrm{HA}$ and $\mathrm{FA}$ in $\mathrm{PhCl}$ solution are depicted in Figure 6 ; the gas-phase data are different in absolute terms but display largely the same trends. Key observations follow.

- Although HA and FA generally increase synchronously, the deviations from linearity are much more pronounced for carbocations. We ascribe this to greater influence of orbital $\pi$-(de)stabilization of carbocations on HA (more covalent) than FA

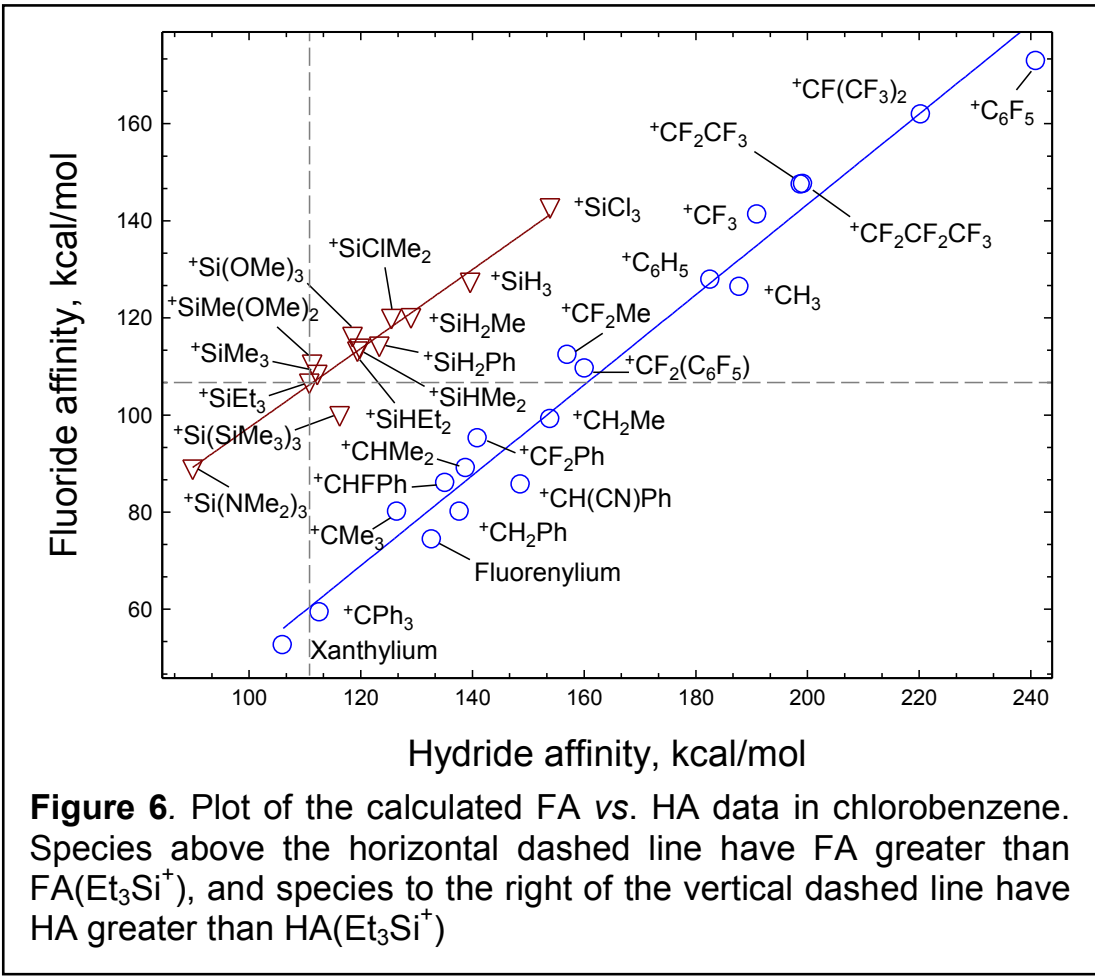
(less covalent) and $\pi$ -

effects being less important for $\mathrm{Si}^{60}$

- The HA and FA values are quite similar for silylium cations. For carbocations, HA is 35-60 $\mathrm{kcal} / \mathrm{mol}$ greater than FA.

- Fluorination of carbocations in the $\alpha$-position has little effect on HA ( $\pi$-donicity of $F$ cancels out the inductive effect) and a moderate effect on HA. $\beta$-Fluorination increases both HA and FA substantially.

- FA of silylium cations is notably greater than that of carbocations with similar substituents. For HA, the inverse difference is even greater and nearly all studied carbocations have HA higher than $\mathrm{Et}_{3} \mathrm{Si}^{+}$.

- FA of pefluorocarbocations is far greater than even that of partly fluorinated carbocations and is 30 $50 \mathrm{kcal} / \mathrm{mol}$ greater than the $\mathrm{FA}$ of $\mathrm{Et}_{3} \mathrm{Si}^{+}$.

- The HDF reactions are very favorable (by $40-60 \mathrm{kcal} / \mathrm{mol}$ ) and the value is fairly independent of the silane. 
- Based on all the data, the hydride transfer from Si to $\mathrm{C}$ is always thermodynamically favorable, except for a few extremes, and should not ever be a kinetic obstacle in the reaction.

- The calculated enthalpies of transfer of fluoride from $\mathrm{C}$ to $\mathrm{Si}$ are consistent with the experimental results if we assume a significant entropic component and an additional barrier for the liberation of the actual free $\mathrm{Et}_{3} \mathrm{Si}^{+}$from an adduct with anion or solvent. Calculations indicate that the fluoride transfer is inherently responsible for the kinetic barrier. Furthermore, fluoride transfer from PFCs is not even kinetically accessible with $\mathrm{Et}_{3} \mathrm{Si}^{+}$.

- Utilization of silylium cations with more electron-withdrawing groups (alkoxide/siloxide or chloride) closes the gap with the FA of perfluorocarbocations. Cations such as $\mathrm{Cl}_{3} \mathrm{Si}^{+}, \mathrm{MeCl}_{2} \mathrm{Si}^{+}$, $(\mathrm{RO})_{3} \mathrm{Si}^{+}$may provide the needed fluorophilicity for HDF of PFCs.

- The difficulty of fluoride abstraction from various sites in PFCs drops off in the order of $\mathrm{CF}>\mathrm{CF}_{2}>$ $\mathrm{CF}_{3}>\mathrm{CF}_{4}$, i.e., $\mathrm{CF}_{4}$ should be the easiest $\mathrm{PFC}$ to activate.

Gu, W.; McCulloch, B. J.; Reibenspies, J. H.; Ozerov, O. V. "Improved Methods for the Halogenation of the $\left[\mathrm{HCB}_{11} \mathrm{H}_{11}\right]^{-}$Anion", submitted.

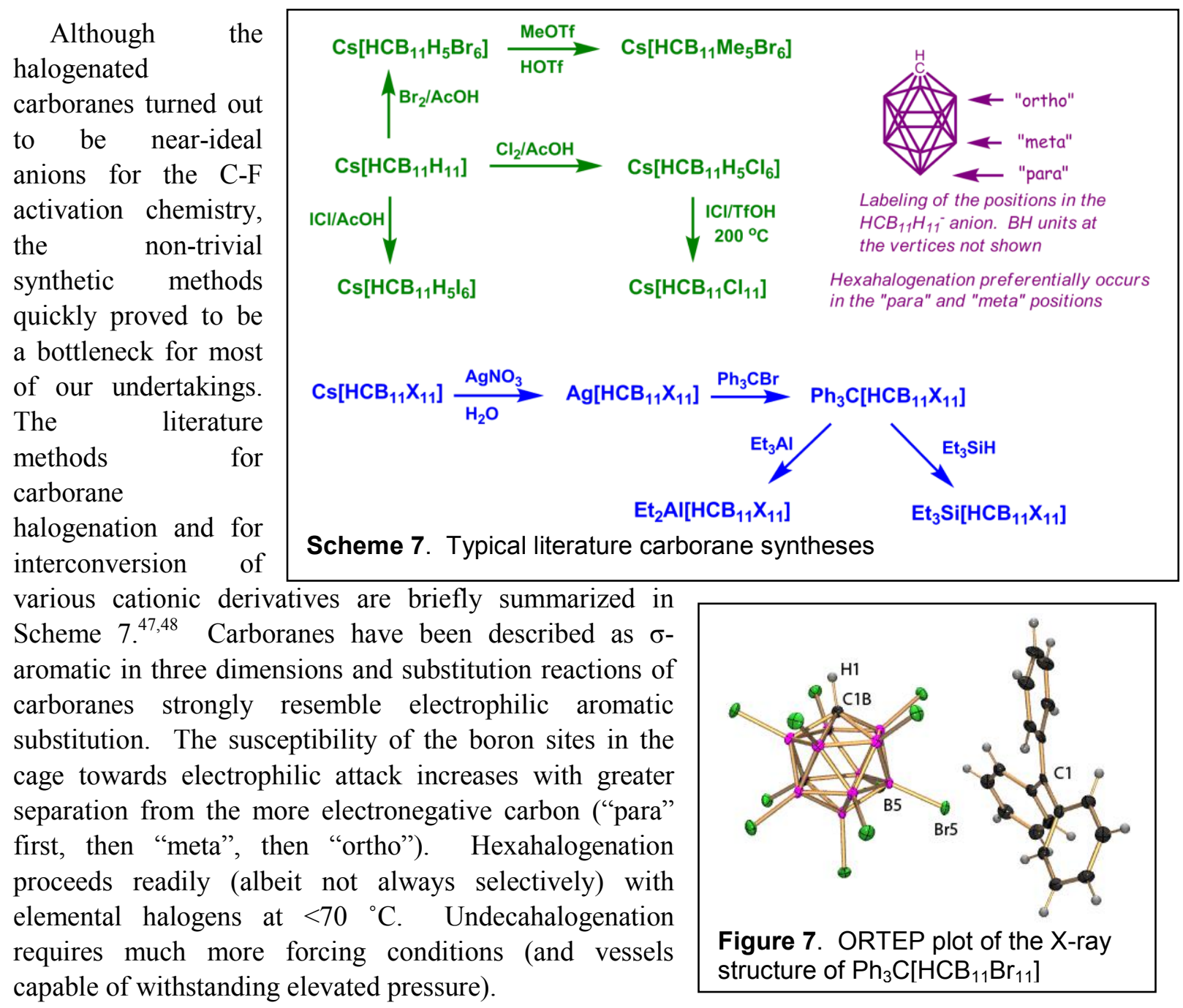


Synthesis of each of the carboranes, while doable, suffers from some combination of hazardous conditions, difficulty in scale-up, great sensitivity to conditions, need for extended but real-time monitoring by ${ }^{11} \mathrm{~B} \mathrm{NMR}$, and also high cost of the reagents and setup. Indeed, improvements in carborane halogenation became essential in order to take our chemistry beyond proof-of-principle experiments. Therefore we threw considerable effort into the development of improved methods. The principles for an ideal synthesis are outlined later, in Section VI. This publication communicates the best of our results that match those principles well. In brief (Scheme 8), undecachlorination of $\left[\mathrm{HCB}_{11} \mathrm{H}_{11}\right]^{-}$to $\left[\mathrm{HCB}_{11} \mathrm{Cl}_{11}\right]^{-}$is simply accomplished by reflux in $\mathrm{SO}_{2} \mathrm{Cl}_{2}$ under argon or by reflux in $\mathrm{SbCl}_{5}$. Undecabromination is accomplished on $1 \mathrm{~h}$ using $\mathrm{Br}_{2} / \mathrm{SbCl}_{5}$ (Figure 7). All of these reactions gave the desired products in $80-90 \%$ yield. The $\mathrm{SO}_{2} \mathrm{Cl}_{2}$ chlorination is very simple - reflux in $\mathrm{SO}_{2} \mathrm{Cl}_{2}$ (bp $=69{ }^{\circ} \mathrm{C}$ ) is followed by removal of excess $\mathrm{SO}_{2} \mathrm{Cl}_{2}$ in vacuo (by-products are gaseous $\mathrm{SO}_{2}$ and $\mathrm{HCl})$ and recrystallization from water. Now, we can routinely produce multigram quantities of $\mathrm{Cs}\left[\mathrm{HCB}_{11} \mathrm{Cl}_{11}\right]$ in about a day. The cost of chlorination is small $\left(\mathrm{SO}_{2} \mathrm{Cl}_{2}\right.$ is $\sim \$ 70 / \mathrm{kg}$ from Aldrich). $\mathrm{Cs}\left[\mathrm{HCB}_{11} \mathrm{H}_{11}\right]$ is available from Katchem (Czech Republic) at $\sim 30 / \mathrm{mmol}$. For comparison, $\mathrm{Na}\left[\mathrm{B}\left(\mathrm{C}_{6} \mathrm{H}_{3}\left(\mathrm{CF}_{3}\right)_{2}\right)_{4}\right]$ is available from

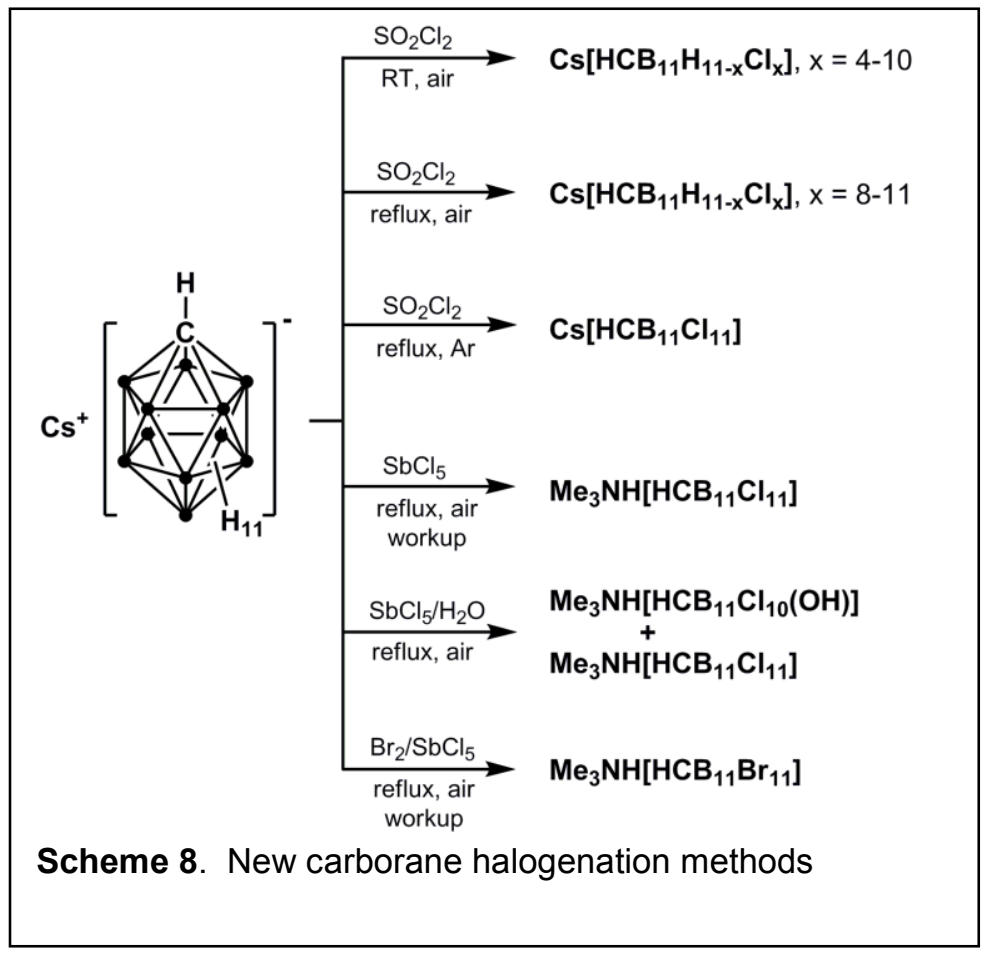
Aldrich for $>\$ 100 / \mathrm{mmol}$.

We want to note that the simplicity hides 18 months of sustained effort on screening numerous conditions and reagents. In the process, we have made a few other useful discoveries, some of which are mentioned separately later.

Germanium chemistry. We have performed a series of experiments on using $\mathrm{Et}_{3} \mathrm{GeH}$ in $\mathrm{HDF}$. Treatment of the mixture of $\mathrm{Et}_{3} \mathrm{GeH}$ and p- $\mathrm{FC}_{6} \mathrm{H}_{4} \mathrm{CF}_{3}$ with $\mathrm{Ph}_{3} \mathrm{C}\left[\mathrm{HCB}_{11} \mathrm{H}_{5} \mathrm{Br}_{6}\right]$ did induce catalytic HDF as evidenced by the formation of $\mathrm{Et}_{3} \mathrm{GeF}$. Although the yield of the latter was consistent with catalysis, the number of observed turnovers was rather limited $(<50)$ and the conversion far from complete. The cause of the poor performance is not clear. In an attempt to isolate trilkylgermylium, abstraction of hydride from $\mathrm{Et}_{3} \mathrm{GeH}$ with $\mathrm{Ph}_{3} \mathrm{C}\left[\mathrm{HCB}_{11} \mathrm{H}_{5} \mathrm{Br}_{6}\right]$ did proceed, presumably to give $\mathrm{Et}_{3} \mathrm{Ge}\left[\mathrm{HCB}_{11} \mathrm{H}_{5} \mathrm{Br}_{6}\right]$. Our efforts to obtain an X-ray quality crystal have not been successful so far, yielding only a crystal of a "bis(water) adduct".

C-C bond formation with Si. We attempted to extend the Si-catalyzed process beyond HDF, to replacement of C-F with C-C bonds. We have not yet been able to

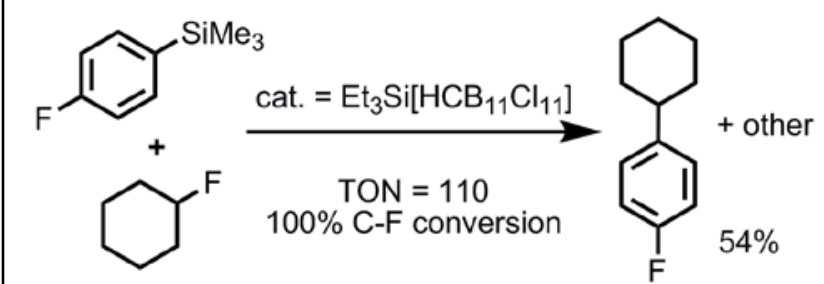

Scheme 9. Representative C-C coupling reaction. catalytically transfer alkyl groups from $\mathrm{Si}$ to $\mathrm{C}$. On the other hand, utilization of $\mathrm{Et}_{3} \mathrm{Si}$ [carborane] as 
catalyst for C-C coupling of aryl- and allyltrimethylsilanes with monofluoroalkanes did lead to the formation of desired products and complete consumption of C-F bonds (Scheme 9). Unfortunately, we have observed formation of side products in all cases; many of them are apparently isomers of the intended products. The reaction can probably be viewed as electrophilic displacement of $\mathrm{Me}_{3} \mathrm{Si}^{+}$by a carbocation (formed via abstraction of fluoride by $\mathrm{X}_{3} \mathrm{Si}^{+}$). Side products may form either from isomerization of alkyl cations or by competitive electrophilic attack on different positions of the aromatic ring. This is essentially analogous to Friedel-Crafts chemistry, but with some ipso-direction by the silyl group.

Indirect impacts of the DOE funding on our group's research. The funding from this grant has allowed us to develop expertise in the synthesis and use of carborane anions, a versatile class of weakly coordinating anions. A property of carboranes that is particularly valuable to an inorganic chemist is their propensity to readily form crystalline salts that are remarkably free of crystallographic disorders. In contrast, tetrarylborates often give rise to oily materials and, when crystalline, are prone to disorder. Because of this, the carborane anions are of great use in isolation of highly reactive, unsaturated transition metal cations not only because of their weak basicity, but also because they allow for the all-important Xray diffraction characterization.

One of the long-standing goals in our group has been the isolation of authentic three-coordinate cations of group 10 metals $[(\mathrm{PNP}) \mathrm{M}]^{+}(\mathrm{M}=\mathrm{Ni}, \mathrm{Pd}$, and $\mathrm{Pt})$. These compounds are exceptionally unusual as 14-electron, three-coordinate cationic complexes of these metals. Moreover, at least for $\mathrm{Ni}$ and $\mathrm{Pd}$, these compounds are paramagnetic. While paramagnetic $\mathrm{Ni}^{\mathrm{iI}}$ compounds in general are common (but not three-coordinate!), paramagnetic $\mathrm{Pd}^{\mathrm{II}}$ complexes are an exotic find! Calculations by Prof. Gusev (Wilfrid Laurier U) confirm the preference for the triplet ground state. The nature of the triplet state can be described as arising from the intramolecular transfer of an electron from the diarylamido ligand-based orbital to the metal orbital that can be conventionally viewed as the "empty site trans to N". We had previously prepared the cationic compounds with the $\left[\mathrm{B}\left(\mathrm{C}_{6} \mathrm{H}_{3}\left(\mathrm{CF}_{3}\right)_{2}\right)_{4}\right]^{-}$anion, but the products were oily substances that resisted crystallization. With carboranes, particularly $\left[\mathrm{HCB}_{11} \mathrm{Cl}_{11}\right]^{-}$, success came quickly and we were able to isolate both the $\mathrm{Pd}$ and the Ni derivatives. Both are paramagnetic in solution, but the carborane is coordinated to the metal in the solid state in the Pd case (Scheme 10). It is likely that the anion dissociates in solution.

Nonetheless, the $\mathrm{Ni}$ derivative is an authentic threecoordinate cation!

With partial support from DOE through a supplement to this grant (DOE funds accounted for $\sim 2 / 3$ of the cost, with the rest coming from private funds), we were able to purchase a glovebox that was dedicated to work in a

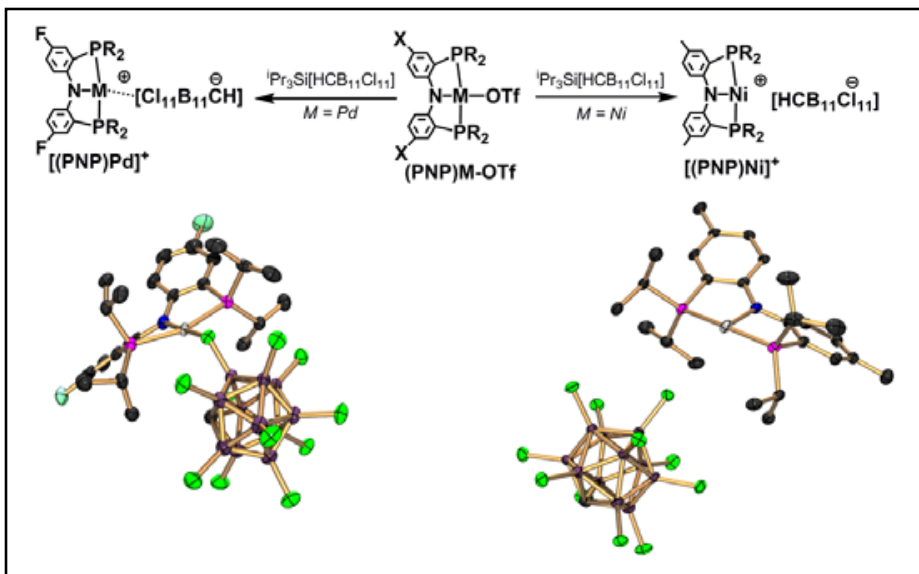

Scheme 10. Isolation of $\mathrm{Ni}$ and $\mathrm{Pd}$ 14-electron cations. 
"Lewis-base free" environment. It was primarily used for the C-F activation chemistry and was indispensable for this DOE project. However, the presence of this glovebox also allows us to work confidently with other highly unsaturated species of interest to our group, such as the complexes described immediately above.

Recognitions received by the PI during the previous period. In 2007, the PI was named a Camille Dreyfus Teacher-Scholar by the Dreyfus foundation. While the following is not truly an accolade, but we would like to note that our 2008 Science publication received substantial coverage in press across the world.

Complete list of publications during the grant period. The complete list of the Ozerov group publications, with links, is online at http:/www.chem.tamu.edu/rgroup/ozerov/

a) Sole funding by DOE-BES and this grant - none. NB: The PI is fortunate to have had a few relatively unrestricted grants from private agencies. They are used to augment support of a variety of projects in the PI's group, including this one. Therefore, all work is partly supported by multiple sources and is listed below, under (b).

b) Joint funding by DOE and other federal or non-federal sources. Publications with DOE as the sole federal source a marked with a **. Other publications acknowledge DOE for reasons of either support of personnel during the writing of the manuscripts or because of use of crucial shared laboratory equipment (e.g., glovebox) purchased in part or in full with DOE funds.

- $\quad{ }^{* *}$ Exhaustive Chlorination of $\left[\mathrm{B}_{12} \mathrm{H}_{12}\right]^{2-}$ without Chlorine Gas and the Use of $\left[\mathrm{B}_{12} \mathrm{Cl}_{12}\right]^{2-}$ as a Supporting Anion in Catalytic Hydrodefluorination of Aliphatic C-F Bonds", Inorg. Chem. 2011, 50, 2726-2728.

- $\quad{ }^{* *}$ Douvris, C.; Nagaraja, C. M.; Chen, C.-H.; Foxman, B. M.; Ozerov, O. V. "Hydrodefluorination and Other Hydrodehalogenation of Aliphatic Carbon-Halogen Bonds Using Silylium Catalysis", J. Am. Chem. Soc. 2010, 132, 4946-4953.

- ${ }^{* *}$ Gusev, D. G.; Ozerov, O. V. " Hydride and Fluoride Affinities of a Series of Carbenium and Silylium Cations in the Gas Phase and $\mathrm{C}_{6} \mathrm{H}_{5} \mathrm{Cl}$ Solution", Chem. Eur. J. 2011, 17, 634-640.

- $\quad{ }^{* *} \mathrm{Gu}$, W.; McCulloch, B. J.; Reibenspies, J. H.; Ozerov, O. V. "Improved Methods for the Halogenation of the [ $\mathrm{HCB}_{11} \mathrm{H}_{11}$ - Anion", Chem. Commun. 2010, 46, 2820-2822 (an Addition/Correction was added later).

- $\quad{ }^{* *} \mathrm{Gu}$, W.; Haneline, M. R.; Douvris, C., "Carbon-Carbon Coupling of $\mathrm{C}\left(\mathrm{sp}^{3}\right)-\mathrm{F}$ Bonds Using Alumenium Catalysis", J. Am. Chem. Soc., 2009, 131, 11203.

- ${ }^{* *}$ Douvris, C.; Ozerov, O. V. "Hydrodefluorination Of Perfluoroalkyl Groups Using Silylium-Carborane Catalysts", Science 2008, 321, 1188.

- Sircoglou, M.; Bontemps, S.; Bouhadir, G.; Saffon, N.; Miqueu, K.; Gu, W.; Mercy, M.; Chen, C.-H.; Foxman, B.; Maron, L.; Ozerov, O. V.; Bourissou, D. "Group 10 and 11 Metal Boratranes (Ni, Pd, Pt, $\mathrm{CuCl}, \mathrm{AgCl}, \mathrm{AuCl}$ and $\mathrm{Au+}$ ) Derived from a Triphosphine-Borane", J. Am. Chem. Soc. 2008, 130, 16729.

- Gatard, S.; Chen, C.-H.; Foxman, B. M.; Ozerov, O. V. "Oxidative Addition Reactions of Silyl Halides with the (PNP)Rh fragment", Organometallics 2008, 27, 6257.

- Bontemps, S.; Bouhadir, G.; Gu, W.; Mercy, M.; Chen, C.-H.; Foxman, B. M.; Maron, L.; Ozerov, O. V.; Bourissou D. "Metallaboratranes Derived from a Triphosphanyl-Borane: Intrinsic $C_{3}$ Symmetry Supported by a Z-Type Ligand", Angew. Chem., Int. Ed. 2008, 47, 1481. 
- Gatard, S.; Guo, C.; Foxman, B. M.; Ozerov, O. V. "Thioether, Dinitrogen, and Olefin Complexes of (PNP)Rh: Kinetics and Thermodynamics of Exchange and Oxidative Addition Reactions", Organometallics, 2007, 26, 6066.

c) Sole funding by other federal or non-federal sources.

- Ozerov, O. V., "Oxidative Addition of Water to Transition Metal Complexes", Chem. Soc. Rev. 2009, 38, 83.

- Radosevich, A. T.; Melnick, J. G.; Stoian, S. A.; Bacciu, D.; Chen, C-H.; Foxman, B. M.; Ozerov, O. V.; Nocera, D. G. "Ligand Reactivity in PNP-Complexes of $\mathrm{Mn}(\mathrm{CO})_{3}$ and $\mathrm{Re}(\mathrm{CO})_{3}$ ", Inorg. Chem. 2009, $48,9214$.

- Whited, M. T.; Zhu, Y.; Timpa, S. D.; Chen, C.-H.; Foxman, B. M.; Ozerov, O. V.; Grubbs, R. H. "Probing the C-H Activation of Linear and Cyclic Ethers at (PNP)Ir", Organometallics 2009, 28, 4560.

- Masuda, J. D.; Jantunen, K. C.; Ozerov, O. V.; Noonan, K. J. T.; Gates, D. P.; Scott, B. L.; Kiplinger, J. L. "A Lanthanide Phosphinidene Complex: Synthesis, Structure, and Phospha-Wittig Reactivity", J. Am. Chem. Soc. 2008, 130, 2408. See a highlight in the February 11th 2008 issue of Chemical and Engineering News 2008, 86(6), 46.

- Zhu, Y.; Fan, L.; Chen, C.-H.; Finnell, S. R.; Foxman, B. M.; Ozerov, O. V. "C-H Oxidative Addition to a (PNP)Ir Center and Ligand-Induced Reversal of Benzyl/Aryl Selectivity", Organometallics 2007, 26, 6701.

- Fafard, C. M.; Chen, C.-H.; Foxman, B. M.; Ozerov, O. V. "Covalent Palladium-Zinc Bonds and Their Reactivity", Chem. Commun. 2007, 4465.

- Gerber, L. C. H.; Watson, L. A.; Parkin, S.; Weng, W.; Foxman, B. M.; Ozerov, O. V. "A Bis(methylidene) Complex of Tantalum Supported by a PNP Ligand", Organometallics 2007, 26, 4866.

- Fafard, C. M.; Adhikari, D.; Foxman, B. M.; Mindiola, D. J.; Ozerov, O. V. "Addition of Ammonia, Water, and Dihydrogen Across a Single Pd-Pd Bond ", J. Am. Chem. Soc., 2007, 129, 10318.

- Weng, W.; Chen, C.-H.; Foxman, B. M.; Ozerov, O. V., "Palladium Complexes of a $\mathrm{P}_{2} \mathrm{C}=$ Ligand Containing a Central Carbene Moiety", Organometallics 2007, 26, 3315.

- Ozerov, O. V.; Watson, L. A.; Pink, M.; Caulton, K. G. "Operationally Unsaturated Pincer/Rhenium Complexes Form Metal Carbenes From Cycloalkenes and Metal Carbynes From Alkanes", J. Am. Chem. Soc. 2007, in press (from postdoctoral work at Indiana U).

- DeMott, J. C.; Basuli, F.; Kilgore, U. J.; Foxman, B. M.; Huffman, J. C.; Ozerov, O. V., Mindiola, D. J. "Silver(I) and Thallium(I) Complexes of a PNP Ligand and Their Utility as PNP Transfer Reagents", Inorg. Chem. 2007, 46, 6271.

- DeMott, J. C.; Guo, C.; Foxman, B. M.; Yandulov, D. V.; Ozerov, O. V., "Five-coordinate aluminum complexes of a PNP ligand", Mendeleev Commun. 2007, 17, 63 (invited contribution to the Higher Chemical College issue).

- Moura, C.; Ozerov, O. V. "Retardation of beta-Hydrogen Elimination in PNP Pincer Complexes of Pd", Inorg. Chim. Acta 2006, 360, 286 (invited contribution for the Next Generation issue).

- Weng, W.; Parkin, S.; Ozerov, O. V. "Double C-H Activation Results in Ru Complexes of a Neutral PCP Ligand With a Central Carbene Moiety", Organometallics 2006, 25, 5345.

- Published book chapter: Ozerov, O. V. "Pincer ligands containing a central amido donor and their transition metal complexes", invited book chapter in Chemistry of the Pincer Complexes (ISBN-10: 0444-53138-6), Elsevier, 2007. 


\section{References.}

${ }^{1}$ (a) Hudlicky, M. Chemistry of Organic Fluorine Compounds; Prentice-Hall: New York, 1992. (b) Hiyama, T. Organofluorine compounds Chemistry and Applications; Springer, New York, 2000. (c) Uneyama, K. Organofluorine Chemistry; Blackwell: Oxford, U.K., 2006.

${ }^{2}$ Ameduri, B.; Boutevin, B. Well-Architectured Fluoropolymers: Synthesis, Properties and Applications, 1st ed.; Elsevier: Amsterdam, 2004.

3 "C-F Bond Activation in Organic Synthesis", Amii, H.; Uneyama, K. Chem. Rev. 2009, 109, 2119-2183.

${ }^{4}$ (a) "Fluorous Catalysis without Fluorous Solvents: A Friendlier Catalyst Recovery/Recycling Protocol Based upon Thermomorphic Properties and Liquid/Solid Phase Separation", Wende, M.; Meier, R.; Gladysz, J. A.. J. Am. Chem. Soc. 2001, 123, 11490-11491. (b) "Fluorous chemistry: from biphasic catalysis to a parallel chemical universe and beyond", Gladysz, J. A.; Curran, D. P. Tetrahedron 2002, 58, 3823-3825. (c) "Chemistry in fluorous media: a user's guide to practical considerations in the application of fluorous catalysts and reagents", Barthel-Rosa, L. P.; Gladysz, J. A. Coord. Chem. Rev. 1999, 190-192, 587-605. (d) "Are teflon "Ponytails" the coming fashion for catalysts?", Gladysz, J. A. Science 1994, 266, 55-56.

${ }^{5}$ Advancing Sustainability through Green Chemistry and Engineering; Lankey, R. L., Anastas, P. T., Eds.; American Chemical Society: Washington, DC, 2002.

${ }^{6}$ (a) "Reductive defluorination of perfluorooctane sulfonate", Ochoa-Herrera V.; Sierra-Alvarez R.; Somogyi A.; Jacobsen N. E.; Wysocki V. H.; Field J. A. Environ. Sci. Technol. 2008, 42, 3260-3264 and references within. (b) "Tracking the pathways of human exposure to Perfluorocarboxylates", Vestergren, R.; Cousins, I.T. Environ. Sci. Technol. 2009, 43, 5565-5575.

${ }^{7}$ (a) "Stratosink-chlorofluoromethane-chlorine atom ozone kill", Molina, M. J.; Rowland, F. S. Nature 1974, 249, 810. (b) "Chlorofluoromethanes in the environment", Rowland, F. S.; Molina, M. J. Rev. Geophys. Space Phys. 1975, 13, 1-35. (c) "Stratospheric ozone in the 21st Century: The chloro-fluorocarbon problem", Rowland, F. S. Environ. Sci. Technol. 1991, 25, 622-628. (d) "Stratospheric Ozone Depletion by Chlorofluorocarbons (Nobel Lecture)", Rowland, F. S. Angew. Chem., Int. Ed. 1996, 35, 1786. (e) "Stratospheric ozone depletion", Rowland, F. S. Phil. Trans. R. Soc. B. 2006, 361, 769-790.

${ }^{8}$ Information on the Montreal protocol can be found at the website of the Ozone Secretariat of the UN Environment Programme: http://ozone.unep.org/

9 "Fixing the Sky", Shiermeier, Q. Nature 2009, 460, 792-795.

10 "The importance of the Montreal Protocol in protecting climate", Velders G. J. M.; Andersen S. O.; Daniel J. S.; Fahey D. W.; McFarland M. Proc. Natl. Acad. Sci. U. S. A. 2007, 104, 4814-4819.

11 "The large contribution of projected HFC emissions to future climate forcing", Velders G. J. M.; Fahey D. W.; Daniel J. S.; McFarland M.; Andersen S. O. Proc. Natl. Acad. Sci. U. S. A. 2009, 106, 10949-10954.

12 "Explicit calculation of indirect global warming potentials for halons using atmospheric models", Youn, D.; Patten, K. O.; Lin, J.-T.; Wuebbles, D. J. Atmos. Chem. Phys. 2009, 9, 8719-8733.

13 "Possible greenhouse effects of tetrafluoromethane and carbon dioxide emitted from aluminum production", Weston, R. E. Jr. Atmos. Environ. 1996, 30, 2901-2910.

14 "The chemistry of volatile waste from silicon wafer processing", Timms, P. L. J. Chem. Soc., Dalton Trans. 1999, 815.

${ }^{15}$ (a) "Infrared band intensities and global warming potentials of $\mathrm{CF}_{4}, \mathrm{C}_{2} \mathrm{~F}_{6}, \mathrm{C}_{3} \mathrm{~F}_{8}, \mathrm{C}_{4} \mathrm{~F}_{10}, \mathrm{C}_{5} \mathrm{~F}_{12}$, and $\mathrm{C}_{6} \mathrm{~F}_{14}$ ", Roehl, C. M.; Boglu, D.; Bruehl, C.; Moortgat, G. K. Geophys. Res. Lett. 1995, 22, 815-18. (b) "Atmospheric Lifetimes of Long-Lived Halogenated Species", Ravishankara, A. R.; Solomon, S.; 
Turnipseed, A.; Warren, R. F. Science 1993, 259, 194-199. (c) "Atmospheric Fate of Hydrofluoroethanes and Hydrofluorochloroethanes: 1. Rate Coefficients For Reactions With OH", Gierczak, T.; Talukdar, R.; Vaghjiani, G. L.; Lovejoy, E. R.; Ravishankara, A. R. J. Geophy. Res. Atmos. 1991, 96, 5001-5011. (d) "Atmospheric Fate of Several Hydrofluoroethanes and Hydrochloroethanes: 2. UV Absorption Cross Sections and Atmospheric Lifetimes", Orlando, J. J.; Burkholder, J. B.; McKeen, S. A.; Ravishanakara, A. R. J. Geophy. Res. Atmos. 1991, 96, 5013-5023.

16 " $\mathrm{CO}_{2}$ Is Not the Only Gas", Shine K. P.; Sturges W. T. Science 2007, 315, 1804-1805.

${ }^{17}$ Intergovernmental Panel on Climate Change's Fourth Assessment Report (2007), Chapter 2, "Changes in Atmospheric Constituents and Radiative Forcing".

${ }^{18}$ IPCC/TEAP Special Report: Safeguarding the Ozone Layer and the Global Climate System: Issues Related to HFCs and PFCs http://www.ipcc.ch/pdf/presentations/briefing-bonn-2005-05/safeguarding-ozonelayer.pdf

${ }^{19}$ http://unfccc.int/ghg_data/ghg_data_unfccc/items/4146.php

${ }^{20} \mathrm{http}$ ://www.epa.gov/highgwp/

21 "Bridging the Montreal-Kyoto Gap ", Cohen, J.; Rau, A.; Bruning, K. Science 2009, 326, 940-941.

22 "Full-energy-chain greenhouse-gas emissions: a comparison between nuclear power, hydropower, solar power and wind power", de van Vate, J. F. Int. J.Risk Ass. Mgmt. 2002, 3, 59-74.

23 "Aerosol Mineralization of Chlorofluorocarbons by Sodium Vapor Reduction", Dufaux, D. P.; Zachariah, M. R. Environ. Sci. Technol. 1997, 31, 2223-2228.

${ }^{24}$ (a) "Innovative Surface Wave Plasma Reactor Technique for PFC Abatement", Hartz, C. L.; Bevan, J. W.; Jackson, M. W.; Wolfford, N. A. Environ. Sci. Technol. 1998, 32, 682-687. (b) "Destructive abatement of $\mathrm{CF}_{4}$ and $\mathrm{C}_{2} \mathrm{~F}_{6}$ via a plasma induced reaction with CaO", Delattre, J. L.; Friedman, T. L.; Stacy, A. M. $J$. Vac. Sci. Technol., B 1999, 17, 2664-2666.

25 (a) "Oxidative destruction of chlorofluorocarbons (CFC11 and CFC12) by zeolite catalysts", Karmaker, S.; Green, H. J. Catal. 1992, 138, 364-376. (b) " Reactivating Effect of Water on Freon 12 Decomposition Catalysts", Imamura, S.; Higashihara, T.; Jindai, H. Chem. Lett. 1993, 1667-1670

26 "Efficient Destruction of $\mathrm{CF}_{4}$ through In Situ Generation of Alkali Metals from Heated Alkali Halide Reducing Mixtures", Lee M. C.; Choi W. Environ. Sci. Technol. 2002, 36, 1367-1371.

27 "A New General Route to Aromatic Fluorocarbons", Gething B.; Patrick C. R.; Stacey M.; Tatlow J. C. Nature 1959, 183, 588-589.

28 "Mineralization of Chlorofluorocarbons and Aromatization of Saturated Fluorocarbons by a Convenient Thermal Process", Burdeniuc, J.; Crabtree, R. H. Science 1996, 271, 340-341.

29 "New and unexpected reactivity of saturated fluorocarbons", MacNicol, D. D.; Roberston, C. D. Nature 1988, 332, 59-61.

${ }^{30}$ (a) "Activation of carbon-fluorine bonds by metal complexes", Kiplinger, J. L.; Richmond, T. G.; Osterberg, C. E. Chem. Rev. 1994, 94, 373. (b) "Recent Advances in C-F Bond Activation", Burdeniuc, J.; Jedlicka, B.; Crabtree, R. H. Chem. Ber. 1997, 130, 145. (c) Richmond, T. G. In Topics in Organometallic Chemistry; Murai, S., Ed.; Springer: New York, 1999; Vol. 3, p 243. (d) "A comparison of C-F and C-H bond activation by zerovalent ni and pt: a density functional study", Reinhold, M.; McGrady, J. E.; Perutz, R. N. J. Am. Chem. Soc. 2004, 126, 5268-5276 and references within. (e) Torrens, H. Coord. Chem. Rev. 2005, 249, 1957. (f) R. N. Perutz, T. Braun in Comprehensive Organometallic Chemistry III, Vol. 1 (Eds.: R. H. Crabtree, M. P. Mingos), Elsevier, Oxford, 2007, pp. 725 - 758. 
31 (a) "Catalytic activation of carbon-fluorine bonds by a soluble transition metal complex", Aizenberg, M.; Milstein, D. Science 1994, 265, 359. (b) "Homogeneous metal-catalyzed hydrogenolysis of C-F bonds", Aizenberg, M.; Milstein, D. J. Am. Chem. Soc. 1995, 117, 8674. (c) "Catalytic C-F Bond Activation of Nonactivated Monofluoroarenes", Young, R. J.; Jr.; Grushin, V. V. Organometallics 1999, 18, 294296. (d) "Hydrodefluorination of Fluorobenzene and 1,2-Difluorobenzene under Mild Conditions over Rhodium Pyridylphosphine and Bipyridyl Complexes Tethered on a Silica-Supported Palladium Catalyst", Yang, H.; Gao, H.; Angelici, R. Organometallics 1999, 18, 2285-2287. (e) C-F activation of fluorinated arenes using NHC-stabilized nickel(0) complexes: selectivity and mechanistic investigations", Schaub, T.; Fischer, P.; Steffen, A.; Braun, T.; Radius, U.; Mix, A. J. Am. Chem. Soc. 2008, 130, 93049317. (f) "Selective Platinum-Catalyzed C-F Bond Activation as a Route to Fluorinated Aryl Methyl Ethers", Buckley, H. L.; Wang, T.; Tran, O.; Love, J. A. Organometallics 2009, 28, 2356-2359.

32 (a) "C-F activation at rhodium boryl complexes: formation of 2-fluoroalkyl-1,3,2-dioxaborolanes by catalytic functionalization of hexafluoropropene.", Braun, T.; Salomon, M. A.; Altenhoner, K.; Teltewskoi, M.; Hinze, S. Angew. Chem., Int. Ed. 2009, 48, 1818-1822. (b) "Catalytic dehalogenation of sp2 C-F and C-Cl bonds in fluoro- and chloroalkenes", Peterson, A. A.; McNeill, K. Organometallics 2006, 25, 4938-4940. (c) "C-F activation and hydrodefluorination of fluorinated alkenes at rhodium", Noveski, D.; Braun, T.; Schulte, M.; Neumann, B.; Stammler, H.-G. Dalton Trans. 2003, 4075-4083.

33 (a) "Ni- or Cu-Catalyzed Cross-Coupling Reaction of Alkyl Fluorides with Grignard Reagents", Terao, J.; Ikumi, A.; Kuniyasu, H.; Kambe, N. J. Am. Chem. Soc. 2003, 125, 5646-5647. (b) "Nickel-Catalyzed Dimerization and Carbosilylation of 1,3-Butadienes with Chlorosilanes and Grignard Reagents", Terao, J.; Todo, H.; Watanabe, H.; Ikumi, A.; Kambe, N. Angew. Chem., Int. Ed. 2004, 42, 3412-3414. (c) "NiCatalyzed Alkylative Dimerization of Vinyl Grignard Reagents Using Alkyl Fluorides", Terao, J.; Watabe, H.; Kambe, N. J. Am. Chem. Soc. 2005, 127, 3656. (d) "Alkylation of Magnesium Enamide with Alkyl Chlorides and Fluorides", Hatakeyama, T.; Ito, S.; Nakamura, M.; Nakamura, E. J. Am. Chem. Soc. 2005, 127, 14192.

34 (a) "Low-Valent Niobium-Mediated Double Activation of $\mathrm{C}-\mathrm{F} / \mathrm{C}-\mathrm{H}$ Bonds: Fluorene Synthesis from $o$ Arylated $\alpha, \alpha, \alpha$-Trifluorotoluene Derivatives", Fuchibe, K.; Akiyama, T. J. Am. Chem. Soc. 2006, 128, 1434-1435. (b) " C-C Coupling Reactions of Superstrong $\mathrm{CF}_{3}$ Groups with $\mathrm{C}\left(\mathrm{sp}^{2}\right)-\mathrm{H}$ Bonds: Reactivity and Synthetic Utility of Zero-Valent Niobium Catalyst", Fuchibe, K.; Mitomi, K.; Suzuki, R.; Akiyama, T. Chem. Asian J. 2008, 3, 261-271

35 (a) "Some reactions of the trifluoromethyl group in the benzotrifluoride series. I. Hydrolysis", Le Fave G. M. J. Am. Chem. Soc. 1949, 71, 4148-4149. (b) "The Thermal Reaction of Hexafluoroethane with Quartz", Grosse, A. V.; Cady, G. H. J. Am. Chem. Soc. 1947, 69, 267-270. (c) "Catalytic Hydrolysis of Dichlorodifluoromethane (CFC-12) on Sol-Gel-Derived Titania Unmodified and Modified with $\mathrm{H}_{2} \mathrm{SO}_{4}$ ", Fu, X.; Zeltner, W. A.; Yang, Q.; Anderson, M. A. J. Catal. 1997, 168, 482-490.

36 (a) "Conversion of 1,1,2-trichlorotrifluoroethane to 1,1,1-trichlorotrifluoroethane and 1,1dichlorotetrafluoroethane over aluminium-based catalysts", Bozorgzadeh H.; Kemnitz E.; Nickkho-Amiry M.; Skapin T.; Winfield J.M. J. Fluor. Chem. 2001, 107, 45-52. (b) "Electrophilic reactions of fluorocarbons under the action of aluminum chlorofluoride, a potent Lewis acid", Petrov V.A.; Krespan C.G.; B.E. Smart J. Fluor. Chem. 1996, 77, 139-142. (c) "Fluorinated metal oxides and metal fluorides as heterogeneous catalysts", Kemnitz, E.; Menz, D.-H. Prog. Solid St. Chem. 1998, 26, 97-153. (d) "Catalytic Synthesis of Chlorofluorocarbon Alternatives", Manzer, L. E.; Rao, V. N. M. Adv. Catal. 1993, 39, 329-350.

37 "Room-Temperature Catalytic Hydrodefluorination of C( $\left.\mathrm{sp}^{3}\right)$-F Bonds", Scott, V. J.; Çelenligil-Çetin, R.; Ozerov, O. V. J. Am. Chem. Soc. 2005, 127, 2852. 
38 (a) "Ion-molecule reactions in silane-tetrafluoromethane mixtures", Krause, J. R.; Lampe, F. W. J. Phys. Chem. 1977, 81, 281-6. (b) "Extensive redistribution of fluorine and hydrogen in the reaction of trifluoromethyl(1+) ions with silane", Krause, J. R.; Lampe, F. W. J. Am. Chem. Soc. 1976, 98, 7826-7.

39 (a) "Modern Approaches to Silylium Cations in Condensed Phase", Lambert, J. B.; Kania, L.; Zhang, S. Chem. Rev. 1995, 95, 1191. (b) "The silylium ion problem, $\mathrm{R}_{3} \mathrm{Si}^{+}$. Bridging organic and inorganic chemistry", Reed, C. A. Acc. Chem. Res. 1998, 31, 325.

${ }^{40}$ (a) "Tetrakis(pentafluorophenyl)borate: a new anion for silylium cations in the condensed phase", Lambert, J. B.; Zhang, S. J. Chem. Soc., Chem. Comm. 1993, 383. (b) "Silyl Cations in the Solid and in Solution", Lambert, J. B.; Zhang, S.; Ciro, S. M. Organometallics 1994, 13, 2430. (c) "The Trimesitylsilylium Cation", Lambert, J. B.; Zhao, Y. Angew. Chem., Int. Ed. 1997, 36, 400. (d) "The Allyl Leaving Group Approach to Tricoordinate Silyl, Germyl, and Stannyl Cations", Lambert, J. B.; Zhao, Y.; Wu, H.; Tse, W. C.; Kuhlmann, B. J. Am. Chem. Soc. 1999, 121, 5001. (e) "The Tridurylsilylium and Tridurylstannylium Cations: Free and Not So Free", Lambert, J. B.; Lin, L. J. Org. Chem. 2001, 66, 8537.

${ }^{41}$ (a) "Closely approaching the silylium ion $\left(\mathrm{R}_{3} \mathrm{Si}^{+}\right)^{+}$, Reed, C. A.; Xie, Z.; Bau, R.; Benesi, A. Science 1993, 262, 402. (b) "Approaching the Silylium $\left(\mathrm{R}_{3} \mathrm{Si}^{+}\right)$Ion: Trends with Hexahalo $(\mathrm{Cl}, \mathrm{Br}, \mathrm{I})$ Carboranes as Counterions", Xie, Z.; Manning, J.; Reed, W. R.; Mathur, R.; Boyd, P. D. W.; Benesi, A.; Reed, C. A. J. Am. Chem. Soc., 1996, 118, 2922-2928. (c) "Novel weak coordination to silylium ions. Formation of nearly linear Si-H-Si bonds", Hoffmann, S. P.; Kato, T.; Tham, F. S.; Reed, C. A. Chem. Commun. 2006, 767-769. (d) "The Silylium Ion Problem $\left(\mathrm{R}_{3} \mathrm{Si}^{+}\right)$: Effect of Substituents R", Xie, Z.; Bau, R.; Benesi, A.; Reed, C. A. Organometallics, 1995, 14, 3933-3941. (e) "[ $\left.\mathrm{Me}_{3} \mathrm{Si}\right]\left[\mathrm{R}-\mathrm{CB}_{11} \mathrm{~F}_{11}\right]$-Synthesis and Properties", Küppers, T.; Bernhardt, E.; Eujen, R.; Willner, H.; Lehmann, C. W. Angew. Chem. Int. Ed. 2007, 46, 6346-6349.

42 "Crystallographic Evidence for a Free Silylium Ion", Kim, K.-C.; Reed, C. A.; Elliott, D. W.; Mueller, L. J.; Tham, F.; Lin, L.; Lambert, J. B. Science 2002, 297, 825.

43 (a) "A Novel $\mathrm{B}\left(\mathrm{C}_{6} \mathrm{~F}_{5}\right)_{3}$-Catalyzed Reduction of Alcohols and Cleavage of Aryl and Alkyl Ethers with Hydrosilanes", Gevorgyan, V.; Rubin, M.; Benson, S.; Liu, J.-X.; Yamamoto, Y. J. Org. Chem. 2000, 65, 6179-6186. (b) "Studies on the Mechanism of $\mathrm{B}\left(\mathrm{C}_{6} \mathrm{~F}_{5}\right)_{3}$-Catalyzed Hydrosilation of Carbonyl Functions", Parks, D. J.; Blackwell, J. M.; Piers, W. E. J. Org. Chem. 2000, 65, 3090-3098.

${ }^{44}$ (a) "General acid-base catalysis of complex reactions in water", Jencks, W. P. Chem. Rev. 1972, 72, 705718. (b) "Acid and Basic Catalysis", Kilpatrick, Jr., M.; Kilpatrick, M. L. Chem. Rev. 1932, 10, 213.

45 (a) "Hydrogen- and fluorine-bridged disilyl cations and their use in catalytic C-F activation", Panisch, R.; Bolte, M.; Mueller, T. J. Am. Chem. Soc. 2006, 128, 9676- 9682. (b) "Hydrodefluorination of nonactivated $\mathrm{C}-\mathrm{F}$ bonds by diisobutyl-aluminiumhydride via the aluminium cation $\left[i-\mathrm{Bu}_{2} \mathrm{Al}\right]^{+}$", Klahn, M.; Fischer, C.; Spannenberg, A.; Rosenthal, U.; Krossing, I. Tet. Lett. 2007, 48, 8900-8903.

46 "Noncoordinating Anions - Fact or Fiction? A Survey of Likely Candidates", Krossing I.; Raabe, I. Angew. Chem. Int. Ed. 2004, 43, 2066-2090.

47 "Chemistry of the Carba-closo-dodecaborate(-) Anion, $\mathrm{CB}_{11} \mathrm{H}_{12}{ }^{-"}$, Körbe, S.; Schreiber, P. J.; Michl, J. Chem. Rev. 2006, 106, 5208.

48 "Carboranes: A New Class of Weakly Coordinating Anions for Strong Electrophiles, Oxidants, and Superacids", Reed, C. A. Acc. Chem. Res. 1998, 31, 133.

49 " $\mathrm{H}^{+}, \mathrm{CH}_{3}{ }^{+}$, and $\mathrm{R}_{3} \mathrm{Si}^{+}$Carborane Reagents: When Triflates Fail", Reed, C. A. Acc. Chem. Res. 2010, 43, 121128.

50 "Carborane acids. New "strong yet gentle" acids for organic and inorganic chemistry", Reed C. A. Chem. Commun. 2005, 1669-1677. 
51 "Isolation of Protonated Arenes (Wheland Intermediates) with BArF and Carborane Anions. A Novel Crystalline Superacid", Reed, C. A.; Fackler, N. L. P.; Kim, K.-C.; Stasko, D.; Evans, D. R.; Boyd, P. D. W.; Rickard, C. E. F. J. Am. Chem. Soc. 1999, 121, 6314-6315.

52 (a) "Stable silylnitrilium ions", Bahr, S. R.; Boudjouk, P. J. Am. Chem. Soc. 1993, 115, 4514-19. (b) "Chemistry of organosilicon compounds. 292. An NMR study of the formation of silyloxonium ions by using tetrakis[3,5-bis(trifluoromethyl)phenyl]borate as counteranion", Kira, M.; Hino, T.; Sakurai, H. $J$. Am. Chem. Soc. 1992, 114, 6697-6700.

53 "Ambient temperature ring-opening polymerization (ROP) of cyclic chlorophosphazene trimer $\left[\mathrm{N}_{3} \mathrm{P}_{3} \mathrm{Cl}_{6}\right]$ catalyzed by silylium ions", Zhang Y.; Huynh K.; Manners I.; Reed C. A. Chem. Commun. 2008, 494496.

54 "Isolating Fluorinated Carbocations", Douvris, C.; Stoyanov, E. S.; Tham, F. S.; Reed, C. A. Chem. Commun. 2007, 1145-1147.

55 "Metal-Mediated Reductive Hydrodehalogenation of Organic Halides", Alonso F.; Beletskaya I. P.; Yus, M. Chem. Rev. 2002, 102, 4009-4092.

${ }^{56}$ (a) "Synthesis, Characterization, and Applications of Group 13 Cationic Compounds ", Dagorne S.; Atwood D. A. Chem. Rev. 2008, 108, 4037-4071. (b) "Synthesis and Characterization of an Almost Linear, Quasi-Two-Coordinate, Cationic Diorganoaluminum Compound", Young, J. D.; Khan, M. A.; Wehmschulte, R. J. Organometallics 2004, 23, 1965. (c) "Two-coordinate Group 13 Element (Al, Ga) Centered Cations Formed by Silyl Group Migration: Synthesis and Characterization", Nakamoto, N.; Shimizu, K.; Sekiguchi, A. Chem. Lett. 2007, 36, 984.

57 "Et $\mathrm{Al}^{+}$Alumenium Ion-like Chemistry. Synthesis and Reactivity toward Alkenes and Alkene Oxides", Kim, K.-C.; Reed, C. A.; Long, G. S.; Sen, A. J. Am. Chem. Soc. 2002, 124, 7662-7663.

${ }^{58}$ (a) "Non-catalytic conversion of C-F bonds of benzotrifluorides to C-C bonds using organoaluminium reagents", Terao, J.; Nakamura, M.; Kambe, N. Chem. Commun. 2009, 40, 6011-6013. (b) "Conversion of a $\left(\mathrm{sp}^{3}\right) \mathrm{C}-\mathrm{F}$ bond of alkyl fluorides to $\left(\mathrm{sp}^{3}\right) \mathrm{C}-\mathrm{X}(\mathrm{X}=\mathrm{Cl}, \mathrm{C}, \mathrm{H}, \mathrm{O}, \mathrm{S}, \mathrm{Se}, \mathrm{Te}, \mathrm{N})$ bonds using organoaluminium reagents", Terao, J.; Begum, S. A.; Shinohara, Y.; Tomita, M.; Naitoh, Y.; Kambe, N. Chem. Commun. 2007, 855-857.

59 (a) " Cocatalysts for Metal-Catalyzed Olefin Polymerization: Activators, Activation Processes, and Structure-Activity Relationships", Chen E. Y. X.; Marks T. J. Chem. Rev. 2000, 100, 1391-1434. (b) "Theoretical studies of the structure and function of MAO (methylaluminoxane)", Zurek, E.; Ziegler, T. Prog. Polym. Sci. 2004, 29, 107-148.

60 " $\pi$-Donation and Stabilizing Effects of Pnictogens in Carbenium and Silicenium Ions - A Theoretical Study of $\left[\mathrm{C}\left(\mathrm{XH}_{2}\right)_{3}\right]+$ and $\left[\mathrm{Si}\left(\mathrm{XH}_{2}\right)_{3}\right]^{+}(\mathrm{X}=\mathrm{N}, \mathrm{P}, \mathrm{As}, \mathrm{Sb}, \mathrm{Bi})$ ", Rissler J.; Hartmann M.; Marchand C.M.; Grützmacher H.; Frenking G. Chem. Eur. J. 2001, 7, 2834-2841. 